\title{
Implementation of Concepts Derived from Model Compound Studies in the Separation and Conversion of Bio-Oil to Fuel
}

\author{
Daniel E. Resasco* and Steven P. Crossley \\ School of Chemical, Biological and Materials Engineering, and \\ Center for Interfacial Reaction Engineering (CIRE), \\ University of Oklahoma, Norman, OK, 73019, USA
}

Keywords: Biomass conversion, bio-oil upgrading strategies, bio-oil fractionation, catalytic stabilization, C-C bond formation, ketonization, aldol condensation, alkylation, hydrodeoxygenation, ring-opening

* Corresponding author

E-mail: resasco@ou.edu 


\section{ABSTRACT}

Thermal conversion of biomass via pyrolysis, torrefaction, or liquefaction is an attractive process with significant economic potential. The main challenge of this technology is the upgrading of the intermediate liquid product (bio-oil) due to its complex composition. The components of bio-oil can be divided into light aqueous soluble oxygenates, furanics, phenolics, sugars and anhydrosugars, and larger oligomers. Since any single upgrading approach can only target the conversion of one or two families of compounds a combination of separation and conversion is necessary.

A number of fundamental studies with model compounds has been done in the last few years and important concepts about reaction mechanisms and nature of active catalysts have been developed. Unfortunately, the complexity of bio-oil has hampered the impact of these fundamental studies on the practical applications. It is an important challenge to predict how each compound or family of compounds will behave over a catalyst in the presence of other families, when the entire mixture is fed. It is important to take into account that catalysts may quickly deactivate if the entire bio-oil is present, even when they were effective in the presence of a more pure stream. This knowledge should help guide the separation to evaluate the most effective catalytic upgrading strategies. The present review highlights recent advancements made with the conversion of model compounds present in bio-oil, as well as strategies to combine this knowledge with separation advancements in an effort to increase the amount of carbon in the biomass that can be economically converted to fuels and chemicals. 


\section{Introduction}

The conversion of biomass to liquid fuels and chemicals through fast pyrolysis, torrefaction, or liquefaction carries great economic potential over alternative methods such as fermentation or gasification [1-3]. These techniques utilize heating in the absence of air to produce solid, liquid, and gas streams. A significant fraction of energy goes into the growth, harvesting, and transportation, but the final liquid product can be converted into fungible fuel if properly upgraded. The challenge lies in the complexity of this liquid stream, which may lead to low liquid yields after upgrading. Biomass fast pyrolysis oil, or bio-oil, contains over 400 different oxygenated compounds with a variety of functional groups [4-6]. These compounds can be divided into several families, including light aqueous soluble oxygenates, furanics, phenolics, sugars and anhydrosugars, and larger oligomers. Unfortunately, any single catalytic approach could only target the conversion of one or two families of compounds to valuable products, while sacrificing the rest to coke or light gases.

The most common upgrading approach is to add hydrogen to the biomass via hydrotreating in an attempt to remove the oxygen while preserving the C-C bonds. Unfortunately, a backbone of six carbons is the lower limit of what can be incorporated into liquid transportation fuels due to the high vapor pressures of short carbon chain hydrocarbons. $40-60 \%$ of the carbon in the bio-oil consists of light oxygenates containing 5 carbons or less. ${ }^{8}$ e.g. formic acid ( 1 carbon); acetic acid, glycolaldehyde (2 carbons); propionic acid, acetol (3 carbons); furan, butanoic acid (4 carbons), furfural, furfuryl alcohol (5 carbons) are among the most abundant compounds in this range.

This means that the most commonly proposed approach of pyrolysis followed by hydrotreating [7] can only convert a fraction of the carbon in the biooil to gasoline range compounds, while wasting the rest as light gases. An alternative approach of promoting condensation reactions to build $\mathrm{C}-\mathrm{C}$ chains would be effective for the conversion of the light molecules containing 5 or fewer carbons to build the carbon chain length up to the gasoline/diesel range. However, the conditions necessary for this condensation also typically favor polymerization of the larger oxygenates to produce a resin that is difficult to upgrade catalytically and ultimately yields low-value coke. Any single catalytic upgrading strategy with the entire bio-oil sacrifices a significant portion of the biomass in an effort to upgrade the rest, which is why single catalytic approaches typically result in a small portion of the carbon in the biomass ending up as liquid hydrocarbon fuel [8].

In order to improve the amount of carbon in the biomass that is converted to valuable liquid products, the various compounds and functional groups present in bio-oil need to be separated, at least to some degree to make them 
controllable. This would allow catalysts and conditions that favor the production of valuable fuel range compounds and chemicals, rather than undesirable losses to polymerization products, coke, and light gases.

Obviously, the introduction of additional separation steps would lead to higher costs. However, the benefits in the net volume of transportation fuel produced from a given amount of biomass resulting from an additional separation step could outweigh the additional processing costs. Since the fraction of carbon lost with current technologies is exceedingly high, there is significant room for process improvement.

The separation of compounds present in bio-oil is not an easy task. Due to the variety of chemical functional groups present, bio-oils are reactive and chemically unstable. Even at room temperature, compounds present in the mixture of bio-oils slowly polymerize and produce resins that cannot be easily upgraded $[8,9]$. Distillation is not an effective route for the separation of components since increased temperatures accelerate polymerization rapidly leading to tar formation. One very simple approach that has been utilized is the addition of a solvent. If a hydrocarbon-based solvent like tetralin or a water/organic solvent mixture is added to the bio-oil, a phase separation results. The more polar compounds partition preferentially in the aqueous phase, while the less polar ones are enriched in the organic phase. Unfortunately, this simple separation does not solve all of the problems since only a small fraction of compounds remain in the organic phase and, more importantly, there is a variety of bio-oil components that are immiscible in both water and organic. For example, starting with a raw bio-oil stream and diluting it in water at high dilution produces a low-viscosity mixture. Upon introducing this dilute stream into a biphasic mixture of a hydrocarbon-based solvent like tetralin and water, the compounds in the bio-oil phase separate into hydrocarbon-soluble, watersoluble, and insoluble fractions. More troublesome, upon heating this dilute stream, a tar with much higher viscosity than the original bio-oil is obtained, despite the high dilution in water and oil. This experiment demonstrates the complexity of the problem of dealing with these compounds in a single mixture.

Additional separation strategies exist, including the sequential condensation of pyrolysis oil vapors [10], more complex solvent extraction [1114], and staged thermal degradation of the biomass [15]. However, one of the important challenges associated with the effectiveness of separation techniques lies in deciding what the targets for separation should be. Should the separation be aimed at creating streams that are more amenable for storage and transportation? or, should they maximize the potential liquid product after catalytic upgrading? Separation is only effective if one knows how to take 
advantage of the compounds that are present and missing from the streams resulting from the separation.

This uncertainty has hampered the impact of fundamental studies with model compounds on the practical applications. Due to the complexity of bio-oils, is a challenge to predict how each compound or family of compounds will behave over a catalyst in the presence of other families, when the entire mixture is fed. This complexity obscures not only the analysis, but the effect of crucial phenomena such as catalyst deactivation and competitive adsorption on catalyst performance. It may have prompted some applied researchers, working with real mixtures to discount the value of model compound studies and leaning to more empirical approaches.

The addition of a catalyst in-situ during the pyrolysis, so-called "catalytic pyrolysis," generates partially upgraded bio-oils with modified characteristics that are easier to separate due to the creation of more hydrophobic product molecules. It is important to note that catalytic pyrolysis is generally viewed as the upgrading of primary pyrolysis vapors, rather than a modification of the pyrolysis process itself, which is responsible for the generation of initial pyrolysis vapors [16]. Therefore, the catalyst essentially is in contact with the entire mixture of primary pyrolysis vapors generated during such processes. Because of this, the location of a catalyst with respect to the primary pyrolysis vapors is an important consideration for reactor design, but will not be the primary focus of this review.

In order to improve the overall process, one should learn from the results from model compounds, but taking into account that catalysts may quickly deactivate if the entire bio-oil is present, even when they were effective in the presence of a more pure stream. This knowledge should help guide the separation to evaluate the most effective catalytic upgrading strategies. The present review highlights recent advancements made with the conversion of model compounds present in bio-oil, as well as strategies to combine this knowledge with separation advancements in an effort to increase the amount of carbon in the biomass that can be economically converted to fuels and chemicals.

\section{Staged and Thermal Fractionation}

In fast pyrolysis, biomass is very rapidly heated to $~ 500^{\circ} \mathrm{C}$ in the absence of air, which converts solid biomass to a liquid bio-oil with liquid yields as high as $70 \%$, with the remaining part of the biomass converted to noncondensable gases, solid char, and ash. Biomass residence time in a fast pyrolysis reactor is typically 1-2 seconds. By contrast, torrefaction is carried out at lower temperatures $\left(200-320^{\circ} \mathrm{C}\right)$ for longer periods of time (i.e., residence time of 
minutes). Torrefaction is generally carried out in order to produce a higher energy density solid, and the water and light gases, which are generated during torrefaction are generally not captured, although they may be used as fuel to heat the biomass.

Fractionation via staged condensation of the bio-oil to obtain multiple, less complex liquid product streams has been proposed by Pollard et al. [17]. In this method, the pyrolysis vapors are sequentially condensed, so the heavier products are condensed first and the lighter ones, later. This approach consists of three traps, maintained at temperatures of 102,77 , and $18^{\circ} \mathrm{C}$, respectively coupled with electrostatic precipitators between each step. By using this approach, some separation of the chemical groups is obtained. For example, the heaviest fraction obtained in the first high temperature trap consists of mainly levoglucosan as well as larger phenolic and sugar oligomers. The final low temperature trap is enriched in acetic acid present in the bio-oil along with several other lighter boiling oxygenates [17].

A limitation of this approach is that the vapor product starts with the entire composition and one could not accomplish a differentiated catalytic upgrading of the different families of compounds. While separation by sequential condensation may minimize some of the complex interactions mentioned above, oligomerization and polymerization in the liquid phase before stabilization may still be a problem.

Alternatively, instead of separating different families of compounds from a common vapor stream by staged condensation of the already pyrolyzed biomass, one can stage the thermal processing of the solid biomass, by carrying out the treatment at successively higher temperatures and producing different vapor product streams, which individually are far less complex than whole pyrolysis oil. These product streams can be catalytically upgraded immediately to less unstable streams, suitable for transportation to further upgrading units or to petroleum refineries. The three fundamental structural polymers of biomass, hemicellulose, cellulose and lignin decompose over different temperature ranges, as shown in Fig. 1, reproduced from ref. [18]. While cellulose is a homopolymer, hemicellulose and lignin are formed from several different momomeric compounds that give rise to broader ranges of decomposition temperatures. Generally, hemicellulose (represented in Fig. 1 by xylan) starts de-polymerizing at the lowest temperature, cellulose at a more distinct intermediate temperature (see sharp derivative peak), and lignin over a broader range, leaning to higher temperatures. These ranges are variable depending on the actual compositions, but also the inter-crosslinking between them as well as other factors, such as the catalytic mineral content. During low temperature torrefaction, hemicellulose is the fraction that predominantly degrades and evolves vapors that include acetic 
acid and furfural as major oxygenates, together with lesser amounts of $\mathrm{C}_{1}-\mathrm{C}_{4}$ oxygenates and anhydrosugars. At intermediate temperatures, degradation of cellulose becomes more prominent and it evolves vapors including levoglucosan and hydroxyacetaldehyde, as well as lesser amounts of smaller oxygenates including acetic acid, furfural, acetol, and others. At the highest pyrolysis temperature, degradation of the (mostly lignin) fractions remaining in the solid results in the evolution of a mixture of singly- and multiply-methoxylated phenolics (e.g., guaiacol, syringol), catechols, phenol, and other lignin monomers, as well as smaller amounts of lignin dimers, trimers, etc. As illustrated in Table 1, preliminary results show that it may be feasible to retain a similar liquid product yield as that from a single high temperature pyrolysis experiment, but with simplified compositions.

\section{Upgrading of different bio-oil fractions}

\subsection{Upgrading of Light acids}

Acetic acid is the most abundant compound in biomass pyrolysis oil [19]. Acetic acid arises primarily from the decomposition of hemicellulose present in the bio-oil, but some acetic acid is produced via the decomposition of the lignin portion of biomass as well [20]. In addition to being the most abundant compound present in bio-oil, acetic acid is also one of the most problematic products [27]. The acidity that accompanies the light carboxylic acids makes the bio-oil corrosive while also accelerating the polymerization of other species in the bio-oil mixture.

Because the light acids contained in bio-oils consist of mostly acetic with some propionic acid containing two to three carbons, any strategies to convert these compounds to fuel-range species must consider either selectively forming alcohols or building the $\mathrm{C}-\mathrm{C}$ chain to the gasoline/diesel range.

\subsubsection{Selective hydrogenation of acetic acid to ethanol.}

One option for the conversion of acetic acid is to hydrogenate it selectively to ethanol. This is a challenging task, as the conditions necessary for the conversion of acids to alcohols are more severe than those necessary for the hydrogenation of most chemical functional groups present in biomass due to the low reactivity of the carboxylic group with hydrogen [21]. At elevated temperatures in the presence of acidic supports, the produced alcohols may also dehydrate to the corresponding olefins, yielding low value light gases.

The hydrogenation of carboxylic acids has been studied over a variety of metals including $\mathrm{Ni}, \mathrm{Cu}, \mathrm{Rh}$, and $\mathrm{Ru}$ [22]. The role of the support has also been investigated. For example, Primo et al. [23] studied the selective hydrogenation 
of acetic acid to ethanol over $\mathrm{Ru}$ supported on $\mathrm{C}$ and $\mathrm{TiO}_{2}$. They observed a three fold increase in TOF when Ru was supported on $\mathrm{TiO}_{2}$. Based on IR data of adsorbed acids over the various catalysts, they proposed that this enhanced activity can be ascribed to the activation of the carboxylic acids over the $\mathrm{TiO}_{2}$ support, followed by hydrogen through the metal function.

\subsubsection{Ketonization of acetic acid to acetone.}

Another very attractive technique used for the upgrading of carboxylic acids it to convert them to ketones through ketonization, also known as ketonic decarboxylation. Through this reaction, two carboxylic acids are converted to a ketone, $\mathrm{CO}_{2}$ and water, as follows:

$\mathrm{R}_{1} \mathrm{COOH}+\mathrm{R}_{2} \mathrm{COOH} \rightarrow \mathrm{R}_{1} \mathrm{COR}_{2}+\mathrm{CO}_{2}+\mathrm{H}_{2} \mathrm{O}$

For a variety of reasons, ketonization is one of the most important reactions to be considered for the conversion of light oxygenates. First, an appealing factor of this reaction is that it does not require hydrogen to remove oxygen. Second, it can be conducted over metal oxides such as $\mathrm{TiO}_{2}$ that are far cheaper than the noble metals typically required for hydrogenation. Third, and most important, the ketonization reaction converts corrosive acids to more stable ketones with a longer carbon backbone. For example, in the ketonization of acetic acid, acetone is the major product. Acetone is an attractive building block that has the potential to enter the transportation fuel range through a variety of routes. Acetone may be selectively hydrogenated to isopropanol, which is more appealing as a direct additive to the gasoline pool for a variety of reasons (high octane, clean burning, low vapor pressure, etc.). Isopropanol may also be used as a liquid phase precursor for alkylation of the lignin derived products to directly incorporate this carbon in the gasoline/diesel fuel range as will be discussed in more detail in section 6 . In addition to the potential conversion to isopropanol, acetone may also undergo direct aldol condensation, either with furanic compounds or with itself, yielding intermediate products that after hydrogenation can be incorporated into the gasoline/diesel range. In summary, the ketonization reaction is a very appealing route to produce compounds that can be incorporated into liquid transportation fuels.

\subsubsection{Ketonization mechanisms on oxide catalysts.}

The mechanism of the ketonization reaction has been a subject of debate over the past few decades. The reaction is known to occur via the decomposition of salts, via surface reactions over reducible oxides, and over zeolites. The mechanism of the ketonization reaction has been the subject of several reviews [24-26] including a recent one from us that highlights the possible mechanisms over oxides and zeolites, as well as potential for this reaction in the upgrading of 
bio-oils [27]. Perhaps, the most controversial mechanistic topic surrounding the ketonization reaction has been about the nature of the active intermediates and active sites necessary for the surface reactions over reducible oxides. Several active intermediates have been proposed as necessary to carry out this reaction by various groups, ranging from ketene and ketene-like species to acid anhydrides, and $\beta$-ketoacids [28-30]. Prominent work in this area was conducted by Ponec an co-workers, who persuasively demonstrated that at least one of the molecules involved in the ketonization requires an a-hydrogen [31]. The importance of the $\alpha$-hydrogen was further emphasized by Nagashima et al. [32]. Recent work by our group and others [33-36, 27] has highlighted the critical role of the active sites in the formation of a $\beta$-ketoacid intermediate prior to decarboxylation. It has been known for long time that $\beta$-ketoacids readily decompose via decarboxylation to produce $\mathrm{CO}_{2}$ and a ketone [37]. The important role of this intermediate in the surface catalyzed ketonization over oxide catalysts is gradually gaining consensus [27].

\subsubsection{Role of the presence of liquid water in ketonization}

A significant advancement in the field pertaining to the utilization of bio-oil is the ability to conduct this reaction in the presence of water. Our group has recently demonstrated that by pre-reducing a $\mathrm{TiO}_{2}$ support, $\mathrm{Ti}$ cations become exposed, thus creating new active sites that catalyze the ketonization reaction even in the presence of liquid water. Fig. 2 shows a proposed reaction mechanism occurring in the presence of water over reduced $\mathrm{TiO}_{2}$ catalysts. By reducing the catalyst in hydrogen and adding $\mathrm{Ru}$ to promote the reduction, the $\mathrm{Ti}^{3+}$ sites generated on the $\mathrm{TiO}_{2}$ surface are stable under aqueous conditions, as has been demonstrated via EPR measurements. Adjacent sites are able to adsorb carboxylic acids and produce the $\beta$-ketoacid intermediate via $\mathrm{C}-\mathrm{C}$ bond formation [36]. This intermediate readily decarboxylates, even under mild aqueous conditions, generating the ketone product. These conclusions have been further supported by our own kinetics studies over a pre-reduced $\mathrm{Ru} / \mathrm{TiO}_{2}$ catalyst, which are consistent with a bimolecular surface reaction [38]. The nature of the reactive intermediate was later investigated in further detail on a series of aliphatic carboxylic acids with varying chain lengths over the same prereduced $\mathrm{Ru} / \mathrm{TiO}_{2}$ catalyst. It was found that the carbon chain length did not have any measurable effect on the heat of adsorption, indicating that the surface carboxylate group is the common feature for all acids regardless of the alkyl chain and responsible for the strong binding to exposed $\mathrm{Ti}^{\mathrm{n}+}$ cations. In addition, a careful analysis of the kinetics indicates an increase in activation enthalpy as the carbon chain length increases from acetic to butyric acid, which is consistent with an early transition state (i.e. C-C bond formation) since a larger alkyl chain will be accompanied by greater steric repulsion and increase the energy required 
to form the $\mathrm{C}-\mathrm{C}$ bond. This result also supports the concept of a $\beta$-ketoacid intermediate, as the subsequent decarboxylation of a formed $\beta$-ketoacid is known to be very energetically feasible and independent of the carbon chain length.

\subsubsection{Ketonization mechanisms on zeolite catalysts.}

The ketonization reaction has also been reported to occur over acidic zeolites, although much less is known of this path when compared with reducible oxides. This reaction is proposed to occur by a primary dehydration over the zeolite to form an acyl species that subsequently reacts with an adjacent adsorbed carboxylate to form the ketone. While the formation of the acyl species has been studied for the more mild Friedl Crafts Acylation reaction, few studies have explored temperatures and environments containing water that would be amenable for biofuels production. One complication from a mechanistic perspective is the rapid aldol condensation that occurs in zeolites under high temperature conditions. In a recent review in the literature, we have proposed the schematic shown in Fig. 3 to explain the ketonization reaction over protonated zeolites [27]. Little is known about the promise for this reaction in the presence of the high water partial pressures that will accompany streams containing carboxylic acids derived from biomass, but this is an important area for investigation in the near future.

\subsection{Stabilization of furanics and other unsaturated heterocyclic compounds}

Fig. 4 illustrates some of the unsaturated heterocyclic compounds present in bio-oil as a result of the dehydration of cellulose and hemicellulose fragments. The most commonly observed heterocyclic compounds contain four-carbon (furan) or five-carbon (pyran) rings. Connected to the ring, they usually contain carbonyl, hydroxyl, or methyl groups, but these compounds never have more than six carbons in the molecule. For example, deriving from hexoses, HMF and maltol have six carbons, deriving from xylose, furfural has five, and furanone has four. Therefore, a simple hydrotreating (HDT) processing of these furanic compounds would only produce light alkanes, with little value as fuel components. Moreover, without a stabilization step, furanic compounds would tend to form humins in the liquid phase and coke at high temperatures. Furanic compounds are generally reactive and, in the presence of the typical acidity of the bio-oil, they tend to promote polymerization and degradation. For example, if left in storage at room temperature for several days, furfural darkens and forms tarry products resulting from polymerization reactions, which become faster at higher temperatures. 
Dealing with the presence of furanic compounds in bio-oil is one of the most challenging tasks for researchers working in the upgrading of bio-oil. Therefore, it is important to investigate the different catalytic approaches available to convert these compounds. First, it is necessary to build up their molecular weight in order to bring them up to the appropriate fuel range (e.g. $\mathrm{C}_{8}$ $\mathrm{C}_{11}$ for gasoline or $\mathrm{C}_{14}-\mathrm{C}_{22}$ for diesel). Then, a hydrodeoxygenation step could be applied to convert the resulting product to hydrocarbons.

\subsection{Condensation of light oxygenates and furanic compounds}

One of the options that bio-oil refiners could have to build-up the carbon chain and incorporate light oxygenates into the fuel pool is the formation of C-C bonds via aldol condensation. In aldol addition, an $\alpha-\mathrm{H}$ is removed from the basic site of the catalyst, generating an enolate that can readily attack the electrophilic end of a carbonyl in a second molecule. Therefore, the aldol reaction requires the presence of an $\alpha-\mathrm{H}$ in one of the molecules condensing and an available $\mathrm{C}=\mathrm{O}$ group in the other. After the aldol addition, the formed dimer can further dehydrate completing the aldol condensation.

Understanding the potential of this interesting strategy requires some detailed discussion and further analysis. For example, Huber et al. [39,40] pointed out that contrary to sugars, which cannot undergo the aldol reaction because the formation of ring structures makes the carbonyl group unavailable, furfural and HMF have readily available $\mathrm{C}=\mathrm{O}$ groups. However, they cannot undergo the self-aldol reaction either because they do not contain an $\alpha-\mathrm{H}$ atom, which is requisite for this reaction. Therefore, these compunds require the presence of an accompanying co-reactant that is able to form a carbanion. We have called attention to the strategic advantage of using acetone in the specific case of bio-oil upgrading [41]. As mentioned above, acetone can be readily obtained by ketonization of acetic acid, an abundant component of bio-oil. Therefore, from a tecnoeconomical point of view, acetone appears as an attractive chemical building block.

The effectiveness of acetone as a co-reactant for furfural and HMF was first demonstrated using a Mg-Al-oxide catalyst prepared by co-precipitaion, producing larger oxygenates. A range of condensation products was obtained. In particular, when one furfural and one acetone condense, the resulting $\mathrm{C}_{8}(\mathrm{FA})$ product is 4-(2-furanyl)-3-buten-2-one. When the $\mathrm{C} 8$ further condenses with another furfural, the $\mathrm{C}_{13}(\mathrm{~F} 2 \mathrm{~A})$ product is 1,5-bis - (2-furanyl) - 1,4-pentadien - 3 one. Replacing furfural with HMF results in the corresponding $\mathrm{C}_{9}$ (or $\mathrm{C}_{15}$ ) products. Subsequent dehydration / hydrogenation can effectively 
hydrodeoxygenate the products, yielding hydrocarbons in the right molecular weight range for fuels $\left(\mathrm{C}_{8}-\mathrm{C}_{15}\right)$.

Following Dumesic's pioneering study, which aimed at the conversion of sugar-derived compounds, the effective combination of aldol condensation of furanics and hydrodeoxygenation has been validated by other groups on different systems. For example, Shen et al. [42] compared the performance of $\mathrm{MgO}^{-} \mathrm{ZrO}_{2}$, $\mathrm{NaY}$, and ammine-substituted $\mathrm{NaY}$ zeolites as catalysts for the condensation of furfural $\left(\mathrm{C}_{5}\right)$ with acetone and propanal $\left(\mathrm{C}_{3}\right)$. They observed that $\mathrm{MgO}-\mathrm{ZrO}_{2}$ resulted in higher selectivity to double aldol-condensation with a ratio of furfuralacetone $\left(\mathrm{FA}, \mathrm{C}_{8}\right)$ to di-furfural-acetone $\left(\mathrm{F} 2 \mathrm{~A}, \mathrm{C}_{13}\right)$ of 0.8 , while $\mathrm{NaY}$ and ammine$\mathrm{NaY}$ gave better selectivity to the $\mathrm{C}_{8}$ product with ratios of $\mathrm{C}_{8}$ to $\mathrm{C}_{13}$ of 2.2 and 9 , respectively. Similarly, Huang et al. [43] investigated a series of $\mathrm{MgO} / \mathrm{NaY}$ catalysts varying $\mathrm{MgO}$ loading, feedstock composition, reaction time and temperature. Their results indicate that the $20 \% \mathrm{MgO} / \mathrm{NaY}$ catalyst was most effective at $85^{\circ} \mathrm{C}$ during $8 \mathrm{~h}$ and could be regenerated after reaction. The ratio of furfural-acetone (FA) to di-furfural-acetone (F2A) products was about $40 / 60$ with the total yield of condensation products near $100 \%$.

\subsubsection{Aldol condensation in biphasic water/organic emulsions}

Adding to these efforts, with the focus in bio-oil upgrading, our group used the novel concept of stabilizing the water/organic oil interface in emulsions with amphiphilic nanoparticles composed of functionalized carbon nanotubes (CNT) fused to metal oxides to catalyze different reactions in each phase [44-47]. By careful synthesis of the nanostructured particles, we were able to place metal catalysts preferentially on the hydrophobic side and basic catalysts on the hydrophilic side. This hybrid configuration can be used to control the selectivity of reactions occurring in one or the other phase for molecules that have low solubility in one of them. Also, increasing the interfacial area between the two phases by generating emulsions, results in higher overall rates of reaction when they are controlled by the rate of mass transfer. Finally, the continuous reaction and separation of products, based on their relative solubilities can be efficiently combined. The amphiphilicity of these nanohybrids is due to the combination of hydrophobicity of the nanotubes with hydrophilicity of the metal oxides [48-52]. These oxides are the catalyst support used during the growth of the nanotubes and can be chosen to be a basic oxide such as $\mathrm{MgO}$ that has aldol condensation activity. By fine-tuning the composition of the nanohybrids, it is possible to tailor the emulsion properties (volume, droplet size, emulsion type), the metal dispersion and location and, therefore, the resulting product distribution [46]. We used these nanohybrid catalyst emulsions for the combined aldol condensation/hydrodeoxygenation reaction in a single reactor. We found that by 
tailoring the catalyst surface, one can improve the overall yield. Among different basic oxides tested as both, supports for the growth of carbon nanotubes and aldol-condensation on their surface, $\mathrm{MgO}$ was most effective. In agreement with previous studies, both the FA $\left(\mathrm{C}_{8}\right)$ and F2A $\left(\mathrm{C}_{13}\right)$ products were observed. It was observed that the Canizzaro reaction is a side reaction in which, by the presence of $\mathrm{OH}$ groups, furfural undergoes disproportionation into the corresponding alcohol and acid. In turn, these products undergo esterification, which yields 2furancarboxylic 2 -furanmethyl ester $\left(\mathrm{C}_{10}\right)$. The most interesting aspect of this study was that the subsequent hydrodeoxygenation of the aldol products was conducted in the same biphasic system (see Fig. 5). By incorporating Pd onto the carbon nanotubes we were able to hydrogenate the aldol-condensation products in the same emulsion system to more stable intermediate products [47]. Subsequently, fully deoxygenated long-chain alkanes (in this case, tridecane) were obtained by increasing the reaction temperature. In the same study, the effect of co-feeding other components typical of bio-oil was investigated. The cofeeds, added to acetone and furfural, included propanal, methanol, acetol, and acetic acid. As expected, the most dramatic inhibition was observed when acetic acid was added to the nanohybrids containing $\mathrm{MgO}$, which essentially eliminated the aldol-condensation activity. This result further supports the above concept of the need for separating different families of compounds.

\subsection{Reductive conversion of furanic compounds}

\subsubsection{Hydrogenation of the carbonyl group.}

In the presence of protons, furanic compounds tend to form dark crosslinked polymers. For example, furfuryl alcohol is thought to polymerize via condensation of the $\mathrm{OH}$ group with the reactive $\mathrm{H}$ at the $\mathrm{C} 5$ position in the furanic ring. The high activity towards this reaction is enhanced by the presence of the $O$ atom and the ring unsaturation. Moreover, the branching and crosslinking that lead to formation of gels of these polyconjugated dark-colored compounds are thought to occur via the interaction

of disubstituted furan rings with non-furanic unsaturated fragments [53 ]. Therefore, if $\mathrm{H}_{2}$ is available, reductive conversion (i.e., hydrogenation and hydrodeoxygenation) catalyzed by metals may be a viable option for reducing the instability of furanic compounds [54]. Sitthisa et al. [55] have pointed out that the selectivity of furanic compound conversion strongly depends on the type of adsorbed surface species that can be stabilized on the catalyst surface. In

addition to the oxygenated functionality, furanics contain the aromatic furanyl ring that can be also hydrogenated. Therefore, metal catalysts that have high affinity for the unsaturated $\mathrm{C}=\mathrm{C}$ bonds catalyze the saturation of the ring. Both, 
geometric and electronic properties of the metals can affect the selectivity towards the different reductive conversion paths.

Group IB metals are less active than Group VIII metals, but significantly more selective towards production of alcohols by hydrogenation of the carbonyl group rather than the furanyl ring. Accordingly, Cu has been the most common IB metal used as a catalyst for hydrogenation of furanics, both in scholarly articles [56-62] as well as industrial patents [63,64]; $\mathrm{Ag}$ and Au have been investigated to a much lesser extent [65]. Cu is much more selective than Ag or other metals in a broad temperature range. Sitthisa et al. [62] studied furfural hydrogenation over a $\mathrm{Cu} / \mathrm{SiO}_{2}$ catalyst showing selectivities to furfuryl alcohol above $98 \%$, even at temperatures above $200^{\circ} \mathrm{C}$. Beyond $250^{\circ} \mathrm{C}$, even $\mathrm{Cu}$ becomes less selective and starts catalyzing other reactions, such as hydrogenolysis. The reason for the high selectivity of $\mathrm{Cu}$ towards carbonyl hydrogenation without saturation of the ring can be explained in terms of the nature of the adsorbate species that can be stabilized on Cu surfaces. Both, theoretical DFT calculations and spectroscopic measurements support the concept that furfural adsorbs on $\mathrm{Cu}$ perpendicular to the surface in a $\eta 1(0)$-aldehyde configuration, as illustrated in Fig. 6.

Using DRIFT spectroscopy, Sitthisa et al. [62] compared the $\mathrm{C}=\mathrm{O}$ stretching vibration frequency of the furfural adsorbed on pure $\mathrm{Cu}$ and that of gas phase furfural. While the latter is $1,720 \mathrm{~cm}^{-1}$ the former appears at around 1,670 $\mathrm{cm}^{-1}$, downshifted 50 wavenumbers, indicating a weakening of the $\mathrm{C}=\mathrm{O}$ bond as a result of the interaction with the surface $[66,67]$. By contrast, the bands corresponding to the vibration of the furanyl ring remained unchanged when compared the adsorbed species and gas phase furfural, which clearly indicates that the furanyl ring is not distorted upon adsorption and does not interact with the metal surface.

\subsubsection{Hydrogenation of the furanyl ring.}

$\mathrm{Pd}$ shows a contrasting behavior with that of $\mathrm{Cu}$. Due to the narrow width and favorable position of its $\mathrm{d}$-band center, $\mathrm{Pd}$ favors the interaction with ethylenic bonds and aromatic rings [68]. As a result, instead of the perpendicular adsorption configuration observed on $\mathrm{Cu}$, furfural can adsorb parallel to the surface, thus allowing the formation of the $\eta^{2}(\mathrm{C}, \mathrm{O})$-aldehyde configuration illustrated in Fig. 6. Experimental evidence for the formation of this species has been provided by surface science observations on single crystals $[69,70]$ as well as by DFT calculations $[71,72]$ that also suggest that the preferred adsorption of furfural on $\mathrm{Pd}(111)$ is in a $\eta 2(\mathrm{C}, \mathrm{O})$-aldehyde configuration with the furanyl ring oriented nearly parallel to the metal surface (see Fig. 7). This configuration makes hydrogenation of the furanyl ring on $\mathrm{Pd}$ readily possible, which would yield the saturated alcohol as the major product. In fact, at low reaction temperatures 
this is experimentally verified. That is, Pd can hydrogenate both the carbonyl group and the furanyl ring, producing tetrahydrofurfuryl alcohol. Ni and Pt also exhibit significant activity and selectivity at low temperatures in both vapor and liquid phases on different supports. For example, Ni catalysts have been used at low temperatures $\left(100{ }^{\circ} \mathrm{C}\right)$ in the liquid phase, exhibiting $>95 \%$ selectivity to furfuryl alcohol $[73,74]$. Likewise, supported Pt catalysts doped with transition metal oxides have exhibited high selectivity, e.g., $\mathrm{Pt} / \mathrm{TiO}_{2} / \mathrm{SiO}_{2}$ (selectivity $=94$ $\%$ ) and $\mathrm{Pt} / \mathrm{ZrO}_{2} / \mathrm{TiO}_{2}$ (selectivity = 95\%) [75], but only at low reaction temperatures.

\subsubsection{Decarbonylation of furfural and HMF.}

A more interesting reaction occurs at higher temperatures on Group VIII metals. In the $\left(\eta^{2}-(\mathrm{C}-\mathrm{O})\right.$ aldehyde) configuration, the carbonyl binds to the metal surface through the carbonyl $\square$ orbital, with overlap between $d$ electrons of the metal and the $\pi^{*}$ orbital of the carbonyl. The back-donation from the metal results in a stronger metal-aldehyde bonding than in the case of the $\eta^{1}$-mode. As the temperature increases, the strongly adsorbed $\eta^{2}$ species is converted into a more stable acyl surface species in which the $C$ atom of the carbonyl remains strongly attached to the surface (see Fig. 6). Interestingly, instead of hydrogenation, this acyl species is the precursor for the decarbonylation reaction, which produces furan and $\mathrm{CO}$. In fact, it has been observed that the selectivity to decarbonylation significantly increases as a function of temperature, which is consistent with an activated conversion of $\eta^{2}(C, O)$ into the acyl species that increases decarbonylation while reducing hydrogenation.

The decarbonylation reaction of furfural to furan has been widely investigated in both, vapor and liquid phases and on metal catalysts such as Pd, $\mathrm{Pt}, \mathrm{Rh}$, and $\mathrm{Ni}[55,76-79]$, in all cases producing high yields at rather mild conditions.

\subsubsection{C-O Hydrogenolysis of furfural.}

If the furanics upgrading strategy uses the aldol-condensation route, the product still requires selective deoxygenation to produce compounds acceptable as components of transportation fuels. A highly desirable outcome of this deoxygenation step is preserving $\mathrm{C}-\mathrm{C}$ bonds while effectively breaking the $\mathrm{C}-\mathrm{O}$ bonds. Therefore, it is important to investigate what catalysts are effective for this task. Catalysts that are only active for hydrogenation, such as $\mathrm{Cu}$, cannot remove $\mathrm{O}$. By contrast, catalysts that are active for decarbonylation, such as $\mathrm{Pd}$ or $\mathrm{Ni}$, result in undesirable carbon losses. Catalysts that are active for C-O hydrogenolysis would be most desirable. For example, furfural could be 
converted into 2-methylfuran, which has intrinsically good fuel properties, i.e., high octane number, $\mathrm{RON}=131$, low water solubility, $7 \mathrm{~g} / \mathrm{L}$ [80].

Sitthisa et al. [81] have recently found that while $\mathrm{Ni}$ is an active catalyst for decarbonylation, the addition of $\mathrm{Fe}$ causes a drastic change in selectivity, lowering the decarbonylation activity and enhancing the selectivity to C-O hydrogenolysis, as illustrated in Fig. 8. Interestingly, it was found that the hydrogenolysis reaction occurs after furfural has been hydrogenated to furfuryl alcohol. That is, when the characteristic decarbonylation activity of $\mathrm{Ni}$ is suppressed, the only reaction that remains for furfural is $\mathrm{C}=\mathrm{O}$ hydrogenation. Subsequently, the resulting alcohol is readily converted to methylfuran via C-O hydrogenolysis. The selectivity to 2-methylfuran is an interesting case. Since the $\mathrm{C}_{1}-\mathrm{O}_{1}$ hydrogenolysis occurs only on furfuryl alcohol and this product is not favored on pure $\mathrm{Ni}$, particularly at the high temperatures required for $\mathrm{C}-\mathrm{O}$ hydrogenolysis, very small amounts of 2-methylfuran are produced on monometallic $\mathrm{Ni}$. This situation is radically changed when $\mathrm{Fe}$ is added to the $\mathrm{Ni}$ based catalysts. Ni-Fe alloy catalysts produce 2-methylfuran in high yields and high selectivity. DFT calculations suggest that the oxophilic nature of $\mathrm{Fe}$ makes the di-bonded $\eta^{2}(\mathrm{C}, \mathrm{O})$-furfural more stable than on the pure Ni surface. The longer $\mathrm{C}_{1}-\mathrm{O}_{1}$ bond length of the adsorbed $\eta^{2}(\mathrm{C}, \mathrm{O})$-furfuryl alcohol indicates that the overall stronger interaction of the $\mathrm{C}=\mathrm{O}$ group with the $\mathrm{Ni}-\mathrm{Fe}$ alloy surface results in the weakening of the $\mathrm{C}_{1}-\mathrm{O}_{1}$ bond, which favors the $\mathrm{C}-\mathrm{O}$ bond cleavage during hydrogenolysis.

\subsubsection{Furanyl ring opening.}

A reaction that has received a great deal of attention in recent years is the acid-catalyzed ring opening of furfuryl alcohol and HMF to produce levulinic acid. As shown in Fig. 9 for the case of furfuryl alcohol, this reaction is believed to

proceed by a series of hydration and dehydration steps, which result in the opening of the furfuryl ring and formation of levulinic acid [54,82]. Serrano et al. [83] have proposed a conversion strategy for levulinic acid that results in high yields of nonanone, which could be readily converted into diesel or gasoline components. First, they found that, over a Ru/C catalyst, levulinic acid can be converted to gamma valerolactol (GVL) in high yield and selectivity. Subsequently, GVL can be ring opened to pentanoic acid, which is finally condensed into the $\mathrm{C} 9$ ketone via decarboxylative ketonization. They found that $\mathrm{Pd} / \mathrm{Nb}_{2} \mathrm{O}_{5}$ can catalyze the direct conversion of GVL to nonanone, but much higher selectivity is obtained if this step is conducted in two separate steps, i.e. ring opening of GVL followed by ketonization of the pentanoic acid on $\mathrm{CeZrO}_{2}$.

Ring opening of furanics can also be accomplished on metal catalysts by different pathways, as shown in Fig. 10. If hydrodeoxygenation occurs before the 
ring opening, the products obtained are largely alcohols, such as butanol and 2pentanol. If only hydrogenation, without deoxygenation, precedes the ring opening, 1,5-pentanediol is obtained. Alcohols may have value as gasoline components; diols can be used as co-monomers in the production of polyesters and polyurethanes [84].

Among the metal catalysts able to catalyze the ring opening reaction, one can mention Ni [55 ,85], Rh [86], Pt [87], and Cu-chromite [58]. The selection of catalyst determines which of the pathways in Fig. 10 can be preferentially followed. For instance, butanol is produced from furfural on $\mathrm{Ni}$ catalysts, on which the reaction starts with decarbonylation, yielding furan that can be ringopened to butanol. By contrast, 1,5-pentanediol and 2-pentanol are obtained when the first steps in the reaction sequence are hydrogenation and hydrogenolysis, respectively. For example, butanal, butanol, and butane, which are derived from the ring opening of furan are observed as main products from the conversion of furfural over a Ni/SiO${ }_{2}$ catalyst at $>200{ }^{\circ} \mathrm{C}$. On this catalyst, furfural decarbonylation to furan is readily catalyzed at these high temperatures [55]. On the other hand, at lower temperatures $\left(140^{\circ} \mathrm{C}\right)$ hydrogenation of furfural to furfuryl alcohol is preferred over $\mathrm{Ni}$ catalysts. As a result, at low temperatures the ring opening produces mainly 1,5-pentandiol. Recent studies conducted by Tomishige's group [86] on $\mathrm{Rh} / \mathrm{SiO}_{2}$ catalysts for the ring opening of furanics in an aqueous solution has shown that saturation of the furanyl ring occurs first, followed by ring opening at a very low rate resulting in low yields of 1,2pentanediol. However, after the addition of $\mathrm{MoO}_{x}$, a remarkable increase in activity was observed and the product selectivity shifted from 1,2-pentanediol to 1,5-pentanediol (> $93 \%$ selectivity). This interesting change in selectivity was explained in terms of the interaction of the tetrahydrofurfuryl alcohol with oxophilic $\mathrm{MoO}_{x}$ species and cleavage of the $\mathrm{C}-\mathrm{O}$ bond catalyzed by neighboring $\mathrm{Rh}$ sites. The general concept is that the noble-metal is partially covered by the low-valent metal oxide. Thus, the interface of the two species constitutes the bifunctional catalytically active site. Accordingly, the $\mathrm{C}-\mathrm{O}$ hydrogenolysis would start by the interaction of the alcohol with the metal oxide moieties resulting in the formation of a terminal alkoxide. Subsequently, the C-O cleavage would be catalyzed by the adjacent noble-metal [88]. These authors expanded the concept to similar pairs of noble-metal/low-valent metal oxides, such as $R h-R e, I r-R e$, and Rh-Mo, which seem to result in comparable yields and selectivities [89-93].

As a result, one can conclude that, depending on the reaction temperature and the metal chosen as a catalyst for reductive conversion, it is possible to chose whether one can produce furanyl alcohols (carbonyl hydrogenation), saturated furanyl rings (ring hydrogenation), furan (decarbonylation), 
deoxygenated products that preserve the number of carbons (hydrogenolysis), or open-chain alcohols (ring opening).

\subsection{Conversion of Phenolics}

The decomposition of lignin present in biomass yields a variety of phenolic compounds that typically contain from one to three oxygenated functional groups in the form of phenolic $\mathrm{OH}$ groups or methoxy groups attached to the ring. The conversion of phenolics is very appealing due to their chemical similarity to gasoline, as they contain an aromatic ring with an already existing $\mathrm{C}-\mathrm{C}$ backbone that would result in a product that could be incorporated into the gasoline pool upon deoxygenation. The greatest challenges are associated with the deactivating nature of these compounds, the selective removal of the strongly bound phenolic $\mathrm{OH}$ groups without consuming excessive hydrogen to saturate the aromatic ring, and the preservation of $\mathrm{C}$ contained in methoxy groups so they are incorporated into the liquid fuel range.

\subsubsection{Conversion of methoxy groups.}

Because phenolic compounds present in bio-oil typically contain one to two methoxy groups attached to the ring, traditional hydrotreating cleaves these methoxy groups from the ring to produce low-value light gases. While the portion of lignin in the biomass can vary from 10 to over $40 \%$ of the biomass, the methoxy groups account for $10-15 \%$ of the carbon of the phenolic compounds resulting from this fraction. This could be a significant gain, as the preservation of the carbon present in methoxy groups has the potential to increase overall carbon yields arriving in the liquid fuel by $10 \%$ [8].

An effective strategy for the preservation of methoxy carbon in the liquid fuel range is to incorporate acidity into the catalyst to promote disproportionation and transalkylation reactions. Several studies have investigated the reaction pathways of methoxyphenols over acidic zeolites [94-98], with conflicting theories regarding the monomolecular disproportionation vs. bimolecular pathways [99102]. A recent kinetic study by Zhu et al. [103] compared both pathways with the methoxy containing aromatic compound anisole and blends of anisole with phenol over HZSM-5. By creating kinetic models with both options and attempting to fit reaction data obtained in the gas phase at $400^{\circ} \mathrm{C}$, they concluded that the monomolecular pathway was negligible.

One challenge associated with the introduction of acidity to a stream of phenolic compounds is the rapid catalyst deactivation that typically occurs due to the strong adsorption of phenolics to acidic catalysts including zeolites [104]. One approach for alleviating these challenges is to introduce a metal capable of dissociating hydrogen, and coupling this with the acid function $[105,106]$. This 
approach not only extends catalyst lifetime, but also results in some deoxygenation of phenolic $\mathrm{OH}$ groups.

\subsubsection{Phenolics over metals supported on reducible oxides.}

An alternative to the combined zeolite/metal approach is to incorporate a reducible oxide support. Boonyasuwat et al. [107] recently studied the conversion of the methoxyphenolic compound guaiacol over $\mathrm{Ru}$ catalysts supported on a variety of supports including carbon, $\mathrm{SiO}_{2}, \mathrm{Y}-\mathrm{Al}_{2} \mathrm{O}_{3}$, and $\mathrm{TiO}_{2}$. They found that while comparing the activity of the support alone, $\mathrm{y}-\mathrm{Al}_{2} \mathrm{O}_{3}$ was the most active catalyst for transalkylation to convert guaiacol to methylcatechol, upon the introduction of $\mathrm{Ru}$ metal capable of dissociating hydrogen, the $\mathrm{TiO}_{2}$ supported catalyst resulted in significantly higher activities when compared to Ru supported on other supports. A scheme depicting the products resulting from the conversion of guaiacol over the two functions is illustrated in Fig. 11. After analysis of the metal particle size, it was concluded that the enhanced activity was not due to the dispersion of the metal, but the creation of new active sites that result from the reduction of $\mathrm{TiO}_{2}$ in the presence of a metal capable of dissociating hydrogen.

The nature of these sites were further investigated by Omotoso et al. by preparing a series of catalysts of $\mathrm{Ru} / \mathrm{TiO}_{2}$ with varying metal particle size and exposed metal perimeter surface area. After normalizing the rates to the surface area of the metal as well as the perimeter sites, it was concluded that the new active sites created for the conversion of guaiacol were due not only to the sites located at interface of the metal particle and the $\mathrm{TiO}_{2}$, but also new reduced $\mathrm{Ti}^{3+}$ sites created by spillover of hydrogen to the support [108].

\subsubsection{Phenolic C-O cleavage.}

The conversion of phenolic compounds over metals typically results in excessive hydrogen consumption resulting in saturation of the ring at temperatures below $300^{\circ} \mathrm{C}$. Because the hydrogenolysis of a $\mathrm{C}-\mathrm{O}$ bond in a phenolic compound requires the breaking of the aromaticity of the ring, these bonds inherently are not easily hydrogenated and require severe conditions.

Typical catalysts used in refineries to hydrogenate petroleum feedstocks are sulfided CoMo and NiMo catalysts. While several groups have studied the conversion of phenolic compounds over these conventional catalysts [109], the absence of sulfur present in the bio-oil streams requires the incorporation of $\mathrm{H}_{2} \mathrm{~S}$ into the bio-oil to maintain activity of the catalysts, which is not an ideal situation unless the bio-oils are to be co-processed with petroleum derived streams. This has led many groups to explore the use of noble metal catalysts, for example $\mathrm{Pt}$ and $\mathrm{Pd}$, due to their high reactivity and the absence of a sulfur requirement [110- 
112]. The high costs typically associated with noble metals has led many groups to explore the use of base metals for the HDO of phenolic compounds, while combining base metals with acid sites to target hydrogenation with transalkylation, as mentioned in section 3.5.a [113-116].

A recent breakthrough in the field results in the combination of a base metal with a more oxophilic metal. Nei et al. [117] recently reported high selectivity to toluene from cresol by the use of $\mathrm{Ni}-\mathrm{Fe}$ bimetallic alloys. Interestingly, under conditions that did not thermodynamically limit hydrogenation of the ring, this pathway was greatly suppressed over this catalyst. DFT calculations confirmed that the presence of the Fe had a great influence of the adsorption geometry of the phenolic compound on the catalyst surface, shifting the binding mode to favor adsorption through the phenolic oxygen rather than flat adsorption of the aromatic ring.

While several authors have proposed a combination of hydrogenation or partial hydrogenation coupled with dehydration to explain the production of toluene from cresol, Nei et al. [117] found that by introducing the saturated alcohol, cyclohexanol, over a $\mathrm{Ni} / \mathrm{SiO}_{2}$ catalyst, dehydration of the saturated alcohol was found to not be a significant step. In order to explain both the production of toluene over metals lacking acidity as well as the enhanced selectivity to toluene upon the incorporation of $\mathrm{Fe}$, the authors proposed an alternative pathway for the production of aromatics from phenolic compounds through a tautomerizaiton pathway as indicated in Fig. 12. This pathway involves an initial tautomerization step that can explain how a molecule that tautomerizes and converts the ketone group to the corresponding alcohol, will have a strong driving force to dehydrate to toluene, which may explain why the toluene to methylcyclohexane ratios observed over these catalysts were actually above the equilibrium, which is the opposite trend to what one would expect if the molecules were produced by saturation of the ring followed by dehydration.

\subsubsection{Alkylation of phenolics with light alcohols.}

Following the ketonization step of the small acids, the resulting ketones can be hydrogenated to secondary alcohols, which are known to be effective alkylating agents $[118,119]$. As mentioned above, acetone is an abundant ketonization product from the light fractions of bio-oil. Hydrogenation produces isopropanol, which can be combined with the phenolics fraction from bio-oil to generate alkylphenols in the $\mathrm{C} 10-\mathrm{C} 13$ range. The combined strategy of ketonization, selective hydrogenation, and alkylation is therefore an effective method to incorporate small oxygenates into the desirable carbon-chain fuel range. This approach not only stabilizes the bio-oil by removing acids, but it enhances the carbon retention in the liquid. Alkylation can be conducted in both 
the vapor and the liquid phase. We have shown that $\mathrm{H}$-beta zeolite is an effective catalyst for alkylating cresol with isopropanol in the vapor phase [120]. However, as previously described, re-heating the whole bio-oil or its fractions leads to an increase in the rate of degradation. Therefore, it is desirable to conduct the alkylation reaction in the liquid phase. However, the high water content of bio-oil presents a challenge for catalyst stability in the liquid phase. In a recent study, Nei et al. [120] have shown that by functionalizing HY zeolite with organosilanes a material with superior properties is obtained. After functionalization, the external surface became hydrophobic, the defects on the zeolite were capped and the stability of the zeolite was greatly enhanced. Remarkably, the catalytic activity of the internal acid sites was preserved. By using this functionalized zeolite mono and di alkylated cresols were obtained at $200^{\circ} \mathrm{C}$ in a bi-phasic system in which the water and organic phases created an emulsion stabilized by the hydrophobic zeolites that played the dual role of emulsifiers and alkylation catalysts. Due to the high concentration of watersoluble compounds present in bio-oil and the low water solubility of the targeted products, biphasic emulsions stabilized by catalytic particles are a promising system that maximizes the interfacial exchange area for simultaneous reaction and separation [121-123]. Hydrophobic zeolites tend to preferentially locate at the water/organic oil interface, which not only helps in stabilizing the emulsion but also in enhancing the mass transfer of reactants and products. However, in general, hydrophobization of zeolites results in the loss of Brønsted acid sites, which are essential for alkylation. In the hydrophobization method that was used, the silylation agent octadecyltrichlorosilane (OTS) selectively reacted with silanol groups, leaving the Brønsted acid sites available for reaction.

Table 2 illustrates the different extents of m-cresol alkylation obtained over the parent and functionalized zeolites at $200^{\circ} \mathrm{C}$ after 3 and $22 \mathrm{~h}$ in a batch reactor operating in emulsion [119]. The untreated zeolite showed low activity at the end of the $22 \mathrm{~h}$ reaction period. Interestingly, even after the shorter reaction period ( 3 h), the untreated zeolite had a much lower activity than the silane-functionalized zeolite, which is consistent with the rapid loss in crystallinity observed by XRD. By contrast, the OTS-functionalized zeolite kept its activity and reached almost $100 \%$ conversion after $22 \mathrm{~h}$ of reaction, as expected from the very low losses in crystallinity and acid density observed for this material. The ratios of di- to monoalkylated products are also included in Table 2. Clearly, the multiple- to monoalkylate ratio increases with reaction time on the functionalized zeolite, indicating that mono-alkylates are primary products that are subsequently further alkylated to di-alkylates and even tri-alkylates, to a lower extent.

\subsection{Partial oxidation}


Paradoxically, while the primary goal of bio-oil upgrading is the elimination of oxygen such that the compounds can be incorporated into the fuel stream, a selective oxidation step might be an advantageous strategy if such oxidation results in an enhanced stability of a stream. For example, Xu et al. [124] have proposed a partial oxidation pretreatment of bulk bio-oil with the goal of converting aldehydes to carboxylic acids, which can be further converted via esterification to a more stable and transportable intermediate. However, this approach in general dramatically increases the acidity of the oil, which is already a significant problem, and under certain conditions the increased acidity could conceivably result in excessive polymerization during the oxidation process.

Another potential application of partial oxidation of intermediate products from biomass is in the area of specialty chemicals. For example, the oxidation of HMF can result in furandicarboxylic acid, a building block to produce polymers such as polyethylene 2,5-furandicarboxylate (PEF) from a renewable source, which might serve as a potential substitute for polyethylene paraphtalate (PET) [125]. Another example of a specialty chemical that may be produced from specific biomass-derived compounds is gluconic acid from glucose. Sugar acids such as gluconic acid are used in a variety of applications and industries including polymers to food additives [126-133]. D-gluconic acid is produced via fermentation of glucose, with a market estimated at around 60,000 tons/year [134].

When combined with advancements in separation, some of these specialty chemicals could possibly be produced from biomass using thermochemical means as the primary conversion step. Recent results from our group in collaboration with researchers from lowa State University demonstrate that high concentrations of levoglucosan could be produced after sequential condensation of the biomass vapors and washing to produce a sugar stream, see Fig. 13 [135]. After some mild filtering to remove the suspended solid particles and furanics, the levoglucosan was hydrolyzed produce glucose with $100 \%$ selectivity, followed by partial oxidation to produce gluconic acid, a reaction that is also $100 \%$ selective. This, to the best of our knowledge, is the first study for the conversion of a single high purity specialty chemical via the catalytic partial oxidation of a stream resulting from the pyrolysis of biomass.

\subsection{Competitive Adsorption}

An important consideration within the catalytic upgrading of any bio-oil stream is the role that competitive adsorption plays on the overall chemistry. Because of the diverse nature of compounds present in bio-oil, small concentrations of a particular species can severely modify the chemistry of the process. Understanding the roles of the various functional groups on catalytic 
activity and the resulting surface coverage of the numerous species is a daunting task when working with real bio-oils. Because of this, one of the most important types of studies that can be conducted to bridge the gap between the knowledge that has been obtained with model compounds and more practical feedstocks is to study surrogate mixtures of compounds.

Hakim et al. [136] were among the first to study blends of model compounds as surrogate bio-oil feeds over a ceria zirconia catalyst. They observed a significant inhibition of the ketonization reaction of acetic acid by the incorporation of furfural, even while furfural conversion was low. This is an indication of competitive adsorption occurring over the catalyst under reaction conditions.

Hart et al. [137] recently conducted a study to probe the role of competitive adsorption of the various families of bio-oil compounds over a bifunctional catalyst, nickel supported on ceria zirconia. The results indicate an interesting trend of very different competitive adsorption over the nickel vs. the ceria zirconia support. The rate of conversion of the acid over the Ni was most hindered by the presence of the model compounds furfural and guaiacol and their products, representing the furanic and phenolic groups present in bio-oil. The trend was opposite over the reduced support, however, with acetic acid decreasing the rate of conversion of the phenolic and furanic species, indicating a strong adsorption constant of the acid on the reducible oxide surface. This is a very interesting concept, in that competitive adsorption can play a critical role in the upgrading of real bio-oil streams, and the trends among functional groups should be very different for various catalysts. More importantly, the degree of inhibition of catalytic rates can be remarkably different over the various functions of a bifunctional catalyst.

Studies with real bio-oil streams or even model compounds can be heavily influenced by the presence of trace levels of polymers or other impurities. Hart et al. observed that the deactivating nature of furfural is very dependent on the presence or absence of trace impurities. Trace amounts of polymers present in an aged furfural sample shifted the influence of furanic species from reversibly adsorbed compounds to severely deactivating polymers.

\section{Outlook}

It is obvious to expect that an increased yield of deoxygenated products by keeping the maximum amount of carbon in the fuel range with minimum hydrogen consumption would require higher technological complexity. Desirable research outcomes (higher yields/lower operating costs) could be obtained via the C-C bond formation strategies mentioned above as well as via development of better catalysts and more effective processes. The goal of future research 
should be to obtain experimental data from different conversion strategies combined with technoeconomic evaluation and life-cycle analysis to determine the cost/benefit ratios and make quantitative evaluations of the different approaches. This assessment will guide the decision of what complexity is required for given feedstocks and geographical locations (e.g. proximity to natural gas sources or refineries).

The fractionation strategies proposed so far are a positive step in the direction of dividing the complex problem in a series of simpler ones. However, most of the product streams obtained so far are still complex, highly oxygenated, and unsuitable for either storage or, e.g., direct insertion into a petroleum refinery. With improved fractionation, taken separately, each stream may be much more readily upgraded. With these streams, catalyst deactivation and the formation of oligomers in the liquid may be mitigated.

\section{Acknowledgements}

The Department of Energy is gratefully acknowledged for support under Grant DE-EE0006287 of the Bioenergy Technology Office CHASE program.

\section{References}

[1] T.P. Vispute, H. Zhang, A. Sanna, G. W. Huber, Science 330 (2010) $1222-1227$.

[2] M. Stöcker, Angew. Chem. Int. Ed. 47 (2008) 9200-9211.

[3] R.P. Anex Preprints of Symposia - American Chemical Society, Div. Fuel Chem,. 54 (2009) 704

[4] G. W. Huber, S. Iborra and A. Corma, Chem. Rev., 106 (2006) 40444098.

[5] C.A. Mullen and A.A. Boateng Energy \& Fuels 22 (2008) 2104-2109.

[6] O. Faix, I. Fortmann, J. Bremer,D. Meier. Holz als Roh-und Werkstoff 49 (1991) 213-219. doi: 10.1007/BF02613278

[7] S.B. Jones, J.E. Holladay, C. Valkenburg, D.J. Stevens, C.W. Walton, C. Kinchin, D.C. Elliott, S. Czernik, "Production of Gasoline and Diesel from Biomass via Fast Pyrolysis, Hydrotreating and Hydrocracking: A Design Case" PNNL-18284 (2009) Pacific Northwest National Laboratory, Richland, Washington 99352 U.S. Department of Energy

[8] S. Wan, T. Pham, S. Zhang, L. Lobban, D. Resasco, R. Mallinson, AICHE Journal, 59 (2013) 2275-2285.

[9] J.P. Diebold, S. Czernik, Energy Fuel. 11 (1997) 1081-1091.

[10] A.S. Pollard, M.R. Rover, R.C. Brown, Journal of Analytical and Applied Pyrolysis 93 (2012)129-138.

[11] Y. Wei, H. Lei, L. Wang, L. Zhu, X. Zhang, Y. Liu, S. Chen, B. Ahring Energy Fuels 28 (2014) 1207-1212. 
[12] N.M. Bennett, S.S. Helle, S.J.B. Duff, Bioresour. Technol. 100 (2009) 6059.

[13] S. Wang, Y. Wang, Q. Cai, X. Wang, H. Jin, Z. Luo, Sep. Purif. Technol. $122(2014)$ 248-255.

[14] X. Hu, Y. Wang, D. Mourant, R. Gunawan, C. Lievens, W. Chaiwat, M. Gholizadeh, L. Wu, X. Li, C.Z. Li, AIChE J. 59 (2013) 888-900.

[15] P. de Wild, H. Reith, E. Heeres, Biomass pyrolysis for chemicals. Biofuels, 2 (2011) 185-208.

[16] R. French, S. Czernik Fuel Processing Technology 91 (2010) 25.

[17] A.S. Pollard, M.R. Rover, R. Brown, Journal of Analytical and Applied Pyrolysis, 93 (2012) 129-138.

[18] S. D. Stefanidis, K. G. Kalogiannis, E. F. lliopoulou, C. M. Michailof, P. A. Pilavachi, A. A. Lappas J. Anal. \& Appl. Pyrolysis 105 (2014) 143-150

[19] R. Aguado, M. Olazar, M.J. San Jose, G. Aguirre, J. Bilbao, Ind. Eng. Chem. Res. 39 (2000) 192.

[20] Q. Liu, S. Wang, Y. Zheng, Z. Luo, K. Cen J. Anal. Appl. Pyrolysis 82 (2008) 170-177.

[21] (a) A. J. McAlees and R. McCrindle, J. Chem. Soc. C, (1969) 2425; (b) H. Adkins and H. R. Billica, J. Am. Chem. Soc., 70 (1948) 3118; (c) E. Bowden and H. Adkins, J. Am. Chem. Soc., 56 (1934) 689.

[22] (a) R. L. Augustine, Catal. Today, 37 (1997) 419; (b) M. J. Mendes, O. A. A. Santos, E. Jorda, A. M. Silva, Appl. Catal., A, 217, (2001) 253; (c) H. Ogura, Y. Imanishi, J. Mol. Catal. A: Chem., 178, (2002)105; (d) Y. Pouilloux, A. Piccirilli, J. Barrault, J. Mol. Catal. A: Chem., 108 (1996) 161; (e) K. Tahara, E. Nagahara, Y. Itoi, S. Nishiyama, S. Tsuruya and M. Masai, Appl. Catal., A, 154 (1997) 75; (f) K. Tahara, H. Tsuji, H. Kimura, T. Okazaki, Y. Itoi, S. Nishiyama, S. Tsuruya and M. Masai, Catal. Today, 28 (1996) 267; (g) M. Toba, S. Tanaka, S. Niwa, F. Mizukami, Z. Koppa' ny and L. Guczi, J. Sol-Gel Sci. Technol., 13 (1998) 1037; (h) M. Toba, S. Tanaka, S. Niwa, F. Mizukami, Z. Koppa, L. Guczi, K. Y. Cheah and T. S. Tang, Appl. Catal., A, 189 (1999) 243; (i) M. Jahjah, Y. Kihn, E. Teuma and M. Gomez, J. Mol. Catal. A: Chem., 332 (2010) 106.(j) H. S. Broadbent, G. C. Campbell, W. J. Bartley and J. H. Johnson, J. Org. Chem., 24, (1959) 1847. (k) Z. Zhang, J. E. Jackson and D. J. Miller, Appl. Catal., A, 219 (2001) 89; (I) T. A. Werpy, J. G. Frye, A. H. Zacher and D. J. Miller, (2002) WO Patent 200335582.

[23] A. Primo, P. Concepcion, A. Corma Chem. Commun. 47 (2011) 36133615.

[24] S. Rajadurai, Catal. Rev. - Sci. Eng. 36 (1994) 385.

[25] K.M. Dooley, Catalysis; Spivey, J. J., Roberts, G. W., Eds.; Royal Society of Chemistry: Cambridge, U.K., 2004; Vol. 17, p 293.

[26] M. Renz, Eur. J. Org. Chem. 979 (2005) 31.

[27] T. Pham, T. Sooknoi, S. Crossley, D.E. Resasco, ACS Catal. 3 (2013) 2456-2473.

[28] R. Pestman, R.M. Koster, A. van Duijne, J.A.Z. Pieterse, V. Ponec, J. 
Catal. 168 (1997) 265.

[29] S. Rajadurai, Catal. Rev. 36 (1994) 385.

[30] O. Nagashima, S. Sato, R.Takahashi, T.J. Sodesawa, Mol. Catal A: Chem. 227 (2005) 231.

[31] R. Pestman, R.M. Koster, A. van Duijne, J.A.Z. Pieterse, V. Ponec, J. Catal. 168 (1997) 265.

[32] O. Nagashima, S. Sato, R. Takahashi, T. Sodesawa, J. Mol. Catal A: Chem. 227 (2005) 231.

[33] T.N. Pham, D. Shi, T. Sooknoi, D.E. Resasco, J. Catal. 295 (2012) 169.

[34] A. Pulido, B. Oliver-Tomas, M. Renz, M. Boronat, A. Corma, ChemSusChem 6 (2013) 141.

[35] T.N. Pham, D.Shi, D.E. Resasco, Journal of Catalysis, (Submitted).

[36] A.V. Ignatchenko, E Kozliak ACS Catalysis 2 (2012), 1555

[37] F.A. Bettelheim,W.H. Brown, M.K. Campbell, S.O. Farrell, Book: Introduction to General, Organic and Biochemistry, 9th edition, 2010

[38] T.N.Pham, D.Shi, D.E. Resasco Top. Catal. (2013) DOI: 10.1007/s11244013-0227-7.

[39] G. W. Huber, J. N. Chheda, C. J. Barrett and J. A. Dumesic, Science 308 (2005) 1446

[40] J. N. Chheda, J.A., Dumesic, Catal. Today 123 (2007) 59

[41] T. N. Pham, D. Shi, D. E. Resasco, Appl Catal B: Environmental 145 (2014) 10

[42] W.Q. Shen, G. A. Tompsett, K. D. Hammond, R. Xing, F. Dogan, C. P. Grey, W.C. Conner, S. M. Auerbach, G. W. Huber, Appl Catal A, 392 (2011) 57

[43] X. Huang, Q.Zhang, T.Wang, Q. Liu, L. Ma, Q.Zhang, J Fuel Chem Technol. 40 (2012) 973.

[44] S. Crossley, J. Faria, M. Shen and D.E. Resasco, Science 327 (2010) 68.

[45] M. Shen and D.E. Resasco, Langmuir 25 (2009) 10843.

[46] M.P. Ruiz, J. Faria, M. Shen, S. Drexler, T. Prasomsri and D.E. Resasco, ChemSusChem 4 (2011) 964

[47] P. A. Zapata, J. Faria, M. P. Ruiz, D. E. Resasco, Topics in Catal., 55 (2012) 38-53.

[48] X. M. Li, D. Reinhoudt and M. Crego-Calama, Chem. Soc. Rev. 36 (2007) 1350.

[49] L. Zhang and D.E. Resasco, Langmuir 25 (2009) 4792.

[50] B.P. Binks and J.A. Rodrigues, Angew. Chem. Int. Ed. 44 (2005) 441.

[51] D.E. Tambe and M.M. Sharma, Adv. Colloid Interface Sci. 52 (1994) 1.

[52] J.R. Bragg, US Pat. 5,855,243 (1999).

[53] M. Choura, N. M. Belgacem, A. Gandini, Macromolecules 29 (1996) 38393850.

[54] Y. Nakagawa, M. Tamura, and K. Tomishige, ACS Catal. 3 (2013) 2655

[55] S. Sitthisa, D.E. Resasco, Catal. Lett. 141 (2011) 784-791.

[56] G. Seo, H. Chon, J. Catal. 67 (1981) 424-429. 
[57] R. Rao, A. Dandekar, R.T.K. Baker, M.A. Vannice, J. Catal. 171 (1997) 406-419.

[58] H.Y. Zheng, Y.L. Zhu, B.T. Teng, Z.Q. Bai, C.H. Zhang, H.W. Xiang, Y.W. Li, J. Mol. Catal. A 246 (2006) 18-23.

[59] B.M. Nagaraja, A.H. Padmasri, B. David Raju, K.S. Rama Rao, J. Mol. Catal. A 265 (2007) 90-97.

[60] B.M. Reddy, G.K. Reddy, K.N. Rao, A. Khan, I. Ganesh, J. Mol. Catal. A 265 (2007) 276-282.

[61] W. Huang, H. Li, B. Zhu, Y. Feng, S. Wang, S. Zhang, Ultrason. Sonochem. 14 (2007) 67-74.

[62] S. Sitthisa, T. Sooknoi, Y. Ma, P.B. Balbuena, D.E. Resasco, J. Catal. 277 (2011) 1-13.

[63] S. Samuel, US Pat. 2754304 A (1956)

[64] A. A. Kozinski US Pat. 4185022 A (1980)

[65] P. Claus, Top. Catal. 5 (1998) 51-62.

[66] N.R. Avery, Surf. Sci. 125(1983) 771

[67] L.E. Murillo, and J.G. Chen, Surf. Sci. 602 (2008) 919

[68] M. Neurock, V. Pallassana and R.A. van Santen, J. Am. Chem. Soc. 122 (2000) 1150

[69] Shekhar, R.; Plank, R.V.; Vohs, J.M.; Barteau, M.A. J. Phys. Chem. B 101 (1997) 7939-7951.

[70] S.H. Pang, J. W. Medlin, ACS Catal., 1 (2011) 1272

[71] S. Sitthisa, T. Pham, T. Prasomsri, T. Sooknoi, R. G. Mallinson, D. E. Resasco, J. Catal. 280 (2011) 17

[72] V. Vorotnikov, G. Mpourmpakis, D. G. Vlachos, ACS Catal. 2 (2012) 2496

[73] H. Li, H. Luo, L. Zhuang, W. Dai, M. Qiao, J. Mol. Catal. A. 203 (2003) 267-275.

[74] B. Liaw, S. Chiang, S. Chen, Y. Chen, Appl. Catal. A, 346 (2008) 179-188.

[75] J. Kijeński, J.; Winiarek, P.; Paryjczak, T.; Lewicki, A.; Mikolajska, A. Appl. Catal. A 2002, 233, 171-182.

[76] L. Wambach, M. Irgang, M. Fischer, US Pat. 4,780,552 (1988)

[77] H. Singh, M. Prasad, R.D. Srivastava, J. Chem. Technol. Biotechnol. 30 (1980) 293-296.

[78] R.D. Srivastava, A.K. Guha, J. Catal. 91 (1985) 254-262.

[79] K.J. Jung, A. Gaset, J. Molinier, Biomass 16 (1988) 63-76

[80] Y. Roman-Leshkov, C.J. Barrett, Z.Y. Liu, J.A. Dumesic, Nature Letters 447 (2007) 982.

[81] S. Sitthisa, W. An, D. E. Resasco, J. Catal. 284 (2011) 90-101

[82] J. Horvat, B. Klaić, B. Metelko, V. S $\square$ unjić, V. Tetrahedron Lett. 26 (1985) 2111

[83] J. C. Serrano-Ruiz, D. Wang and J. A. Dumesic, Green Chem. 12 (2010) 574

[84] M. Schlaf, Dalton Trans. (2006) 4645-4653.

[85] V. Vetere, A.B. Merlo, J.F. Ruggera, M.L. Casella, J. Braz, Chem. Soc. 21 (2010) 914-920. 
[86] S. Koso, N. Ueda, Y. Shinmi, K. Okumura, T. Kizuka, K. Tomishige, J. Catal. 267 (2009) 89-92.

[87] C.J. Kliewer, C. Aliaga, M. Bieri,W. Huang, C. Tsung, J.B. Wood, K. Komvopoulos, G.A. Somorjai, J. Am Chem. Soc. 132 (2010) 1308813095.

[88] M. Chia, Y.J. Pagán-Torres, D. Hibbitts, Q. Tan, H.N. Pham, A.K. Datye, M. Neurock, R.J. Davis, J.A. Dumesic, J. Am. Chem. Soc. 133 (2011) 12675.

[89] S. Koso, I. Furikado, A. Shimao, T. Miyazawa, K. Kunimori, K. Tomishige, Chem. Commun. (2009) 2035.

[90] S. Koso, N. Ueda, Y. Shinmi, K. Okumura, T. Kizuka, K.J. Tomishige, Catal. 267 (2009) 89.

[91] K. Chen, S. Koso, T. Kubota, Y. Nakagawa, K. Tomishige, ChemCatChem 2, (2010) 547.

[92] Y. Nakagawa, K. Tomishige, Catal. Today 195 (2012) 136.

[93] K. Chen, K. Mori, H. Watanabe, Y. Nakagawa, K. Tomishige, J. Catal. 294 (2012) 171.

[94] A.G. Gayubo, A.T. Aguayo, A. Atutxa, R. Aguado, J. Bilbao, Ind. Eng. Chem. Res. 43 (2004) 2610-2618.

[95] J.D. Adjaye, N.N. Bakhshi, Biomass Bioenergy 8 (1995) 131-149.

[96] P.D. Chantal, S. Kaliaguine, J.L. Grandmaison, Appl. Catal. 18 (1985) 133-145.

[97] P.A. Horne, P.T. Williams, Renew. Energy 7 (1996) 131-144.

[98] M.A. Peralta, T. Sooknoi, T. Danuthai, D.E. Resasco, J. Mol. Catal. A 312 (2009) 78-86.

[99] J.M. Jacobs, R.F. Parton, A.M. Boden, P.A. Jacobs, Stud. Surf. Sci. Catal. 41 (1988) 221-230.

[100] N. Ballarini, F. Cavani, L. Maselli, A. Montaletti, S. Passeri, D. Scagliarini, C. Flego, C. Perego, J. Catal. 251 (2007) 423-436.

[101] P. Beltrame, P.L. Beltrame, P. Carniti, A. Castelli, L. Forni, Appl. Catal. 29 (1987) 327-334.

[102] M. Marczewski, J.-P. Bodibo, G. Perot, M. Guisnet, J. Mol. Catal. 50 (1989) 211-218.

[103] X. Zhu, R.G. Mallinson, D.E. Resasco, Applied Catalysis A: General 379 (2010) 172-181.

[104] T. Prasomsri, A. To, S. Crossley, W.E. Alvarez, D.E. Resasco, Applied Catalysis B: Environmental 106 (2011) 204-211.

[105] A. Ausavasukhi, T. Sooknoi, D.E. Resasco Journal of Catalysis 268 (2009) 68-78.

[106] A. Ausavasukhi, Y. Huang, A.T. To, T. Sooknoi, D.E. Resasco Journal of Catalysis 290 (2012) 90-100.

[107] S. Boonyasuwat, T. Omotoso, D.E. Resasco, S.P. Crossley. Catalysis Letters 143 (2013) 783-791.

[108] T. Omotoso, S. Boonyasuwat, S.P. Crossley. Green Chemistry 16 (2014)645-652. 
[109] D.C. Elliott, Energy Fuels 21 (2007) 1792-1815.

[110] A.J. Foster, P.T.M. Do, R.F. Lobo, Top. Catal. 55 (2012) 118-128.

[111] X. Zhu, L.L. Lobban, R.G. Mallinson, D.E. Resasco, J. Catal. 281 (2011) 21-29.

[112] C.Zhao, Y.Kou, A.A.Lemonidou, X.B.Li, J.A.Lercher, Chem.Commun. 46, (2010) 412-414.

[113] A. Ausavasukhi, T. Sooknoi, D.E. Resasco, J. Catal. 268 (2009) 68-78.

[114] A. Cho, J. Shin, A. Takagaki, R. Kikuchi, T.S. Oyama, Top. Catal. 55 (2012) 969-980.

[115] C. Zhao, S. Kasakov, J. He, J.A. Lercher, J. Catal. 296 (2012) 12-23.

[116] R.Olcese, M.M.Bettahar, D.Petijean, B.Malaman, F.Giovanella, A.Dufour, Appl. Catal. B 115-116 (2012) 63-73.

[117] L. Nie, P.M. de Souza, F.B. Noronha, W. An, T. Sooknoi, D.E. Resasco. Journal of Molecular Catalysis A: Chemical (2013) in press.

[118] K. S. N. Reddy, B. S. Rao, V. P. Shiralkar, Appl. Catal. A-General, 95 (1993) 53

[119] P. Zapata, J. Faria, M. Ruiz, R. Jentoft, D. Resasco, J. Am. Chem. Soc. 134, (2012) 8570

[120] L. Nie, D. E. Resasco, Appl. Catal. A 447- 448 (2012) 14- 21.

[121] S. Crossley, J. Faria, M. Shen, D. E. Resasco, Science 327 (2010) 68.

[122] J. Faria, M. P. Ruiz, D. E. Resasco, Adv. Synth. Catal. 352 (2010) 2359.

[123] M. P. Ruiz, J. Faria, M. Shen, S. Drexler, T. Prasomsri, D. E. Resasco, ChemSusChem 4 (2011) 964.

[124] Junming Xu, Jianchun Jiang, Weidi Dai, Tianjian Zhang, and Yu Xu Energy Fuels 25 (2011) 1798-1801

[125] E. de Jong, M. A. Dam, L. Sipos, and G.-J. M. Gruter In Biobased Monomers, Polymers, and Materials; Smith, P., et al.; ACS Symposium Series; American Chemical Society: Washington, DC, 2012.

[126] H. Hustede, H.-J. Haberstroh and E. Schinzig, in Ullmann's Encyclopedia of Industrial Chemistry, Wiley-VCH Verlag GmbH \& Co. KGaA, 2000.

[127] S. Ramachandran, P. Fontanille, A. Pandey, C. Larroche, Food Technol. Biotechnol. 44 (2006) 185-195.

[128] C. Baatz and U. Pru $\square$ Be, J. Catal., 249 (2007) 34-40.

[129] B. T. Kusema and D. Y. Murzin, Catal. Sci. Technol., 3 (2013) 297-307.

[130] N. M. Xavier, A. I. P. Rauter and Y. Queneau, Top. Curr. Chem., 295 (2010) 19-62.

[131] S. Van de Vyver and Y. Roman-Leshkov, Catal. Sci. Technol., 3, (2013) $1465-1479$.

[132] N. Thielecke, M. Aytemir and U. Pru $\square$ sse, Catal. Today, 121 (2007) 115120.

[133] K. Marcincinova-Benabdillah, M. Boustta, J. Coudane, M. Vert, Biomacromolecules, 2 (2001) 1279-1284

[134] F.W. Lichtenthaler, Acc. Chem. Res. 35 (2002) 728-737.

[135] D. Santhanaraj, R. Smith, R. Brown, D. Resasco, and S. Crossley (unpublished) 
[136] S.H. Hakim , B. Shanks, J.A. Dumesic, Applied Catalysis B: Environmental 142-143 (2013) 368-376

[137] J. Hart, D.E. Resasco, R. Mallinson, S. Crossley, (unpublished). 
Table 1. Yield of different product fractions as a function of thermal conversion temperatures

(c) 2014.This manuscript version is made available under the Elsevier user license

http:T/:yww.elsevier.comopen-access/userlicense/1, $/ 0 /$

\begin{tabular}{|c|c|c|c|c|}
\hline Temperature ( C) & 240 & 360 & 500 & Cumulative \\
\hline liquid yield (wt. \%) & 9.4 & 41.3 & 18.0 & 50.0 \\
solid yield (wt. \%) & 84.3 & 37.8 & 61.4 & 19.6 \\
gas yield (wt. \%) & 6.1 & 9.6 & 7.9 & 17.2 \\
\hline Total (wt \%) & 99.8 & 88.7 & 87.3 & 86.8 \\
\hline
\end{tabular}


Figure 1. Torrefaction/Pyrolysis

Reproduced from ref. [18]

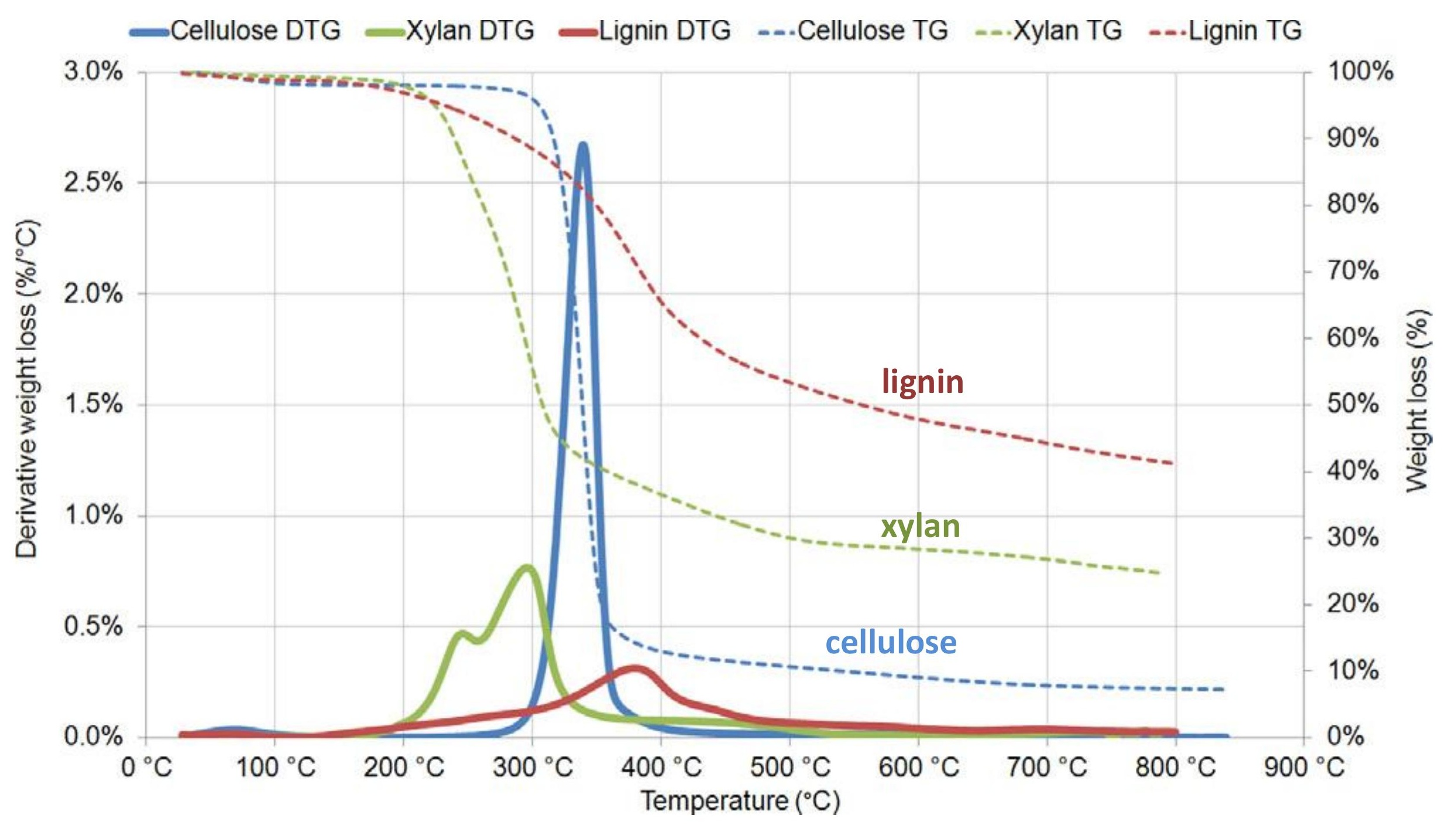




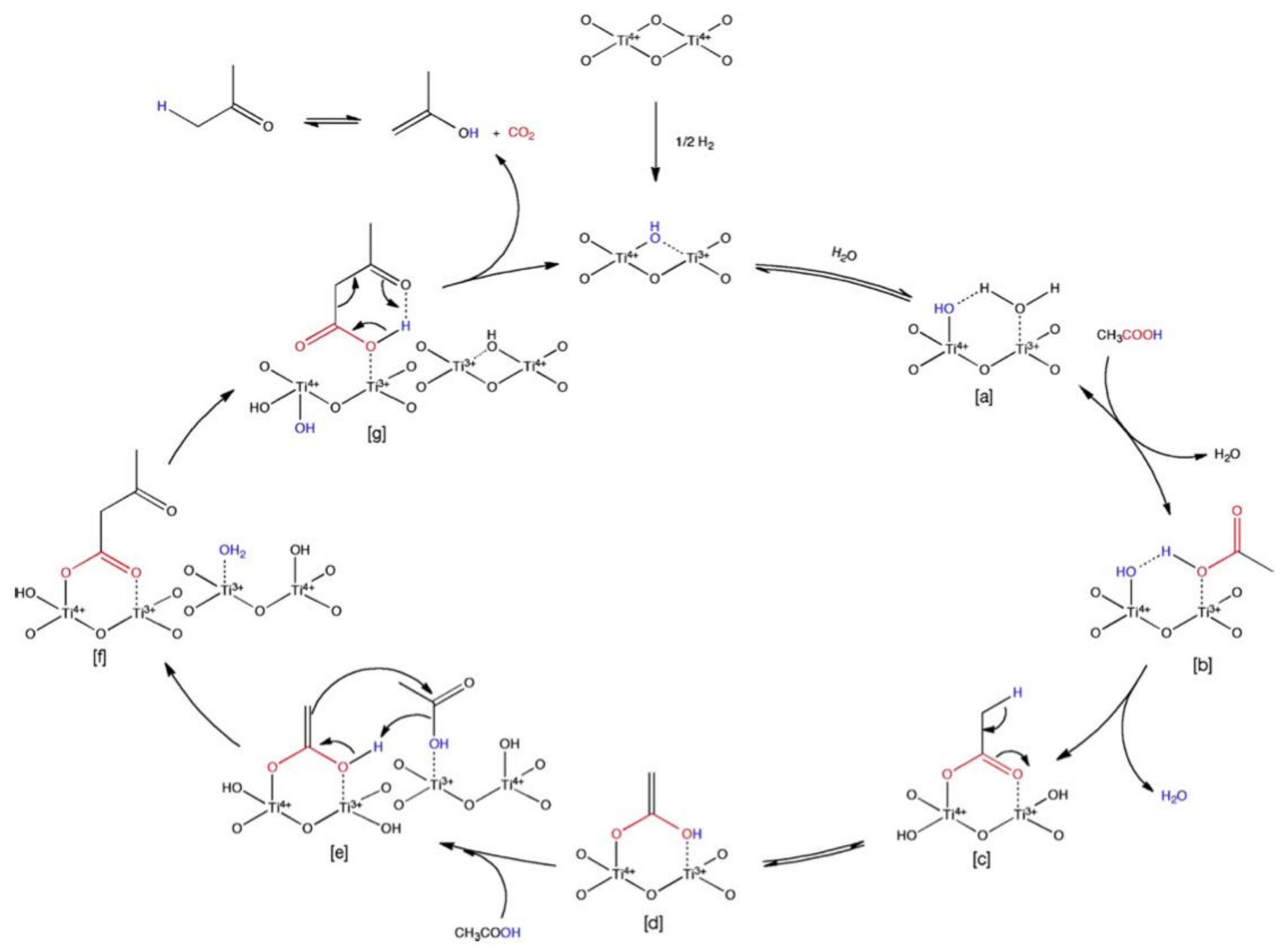

Figure 2: Proposed $\beta$-ketoacid based mechanism for the case of liquid phase ketonization of acetic acid to acetone over $\mathrm{TiO}_{2}$ catalyst [35]. 
Figure 3: Proposed route for acetic acid conversion to acetone over acidic zeolites [27].

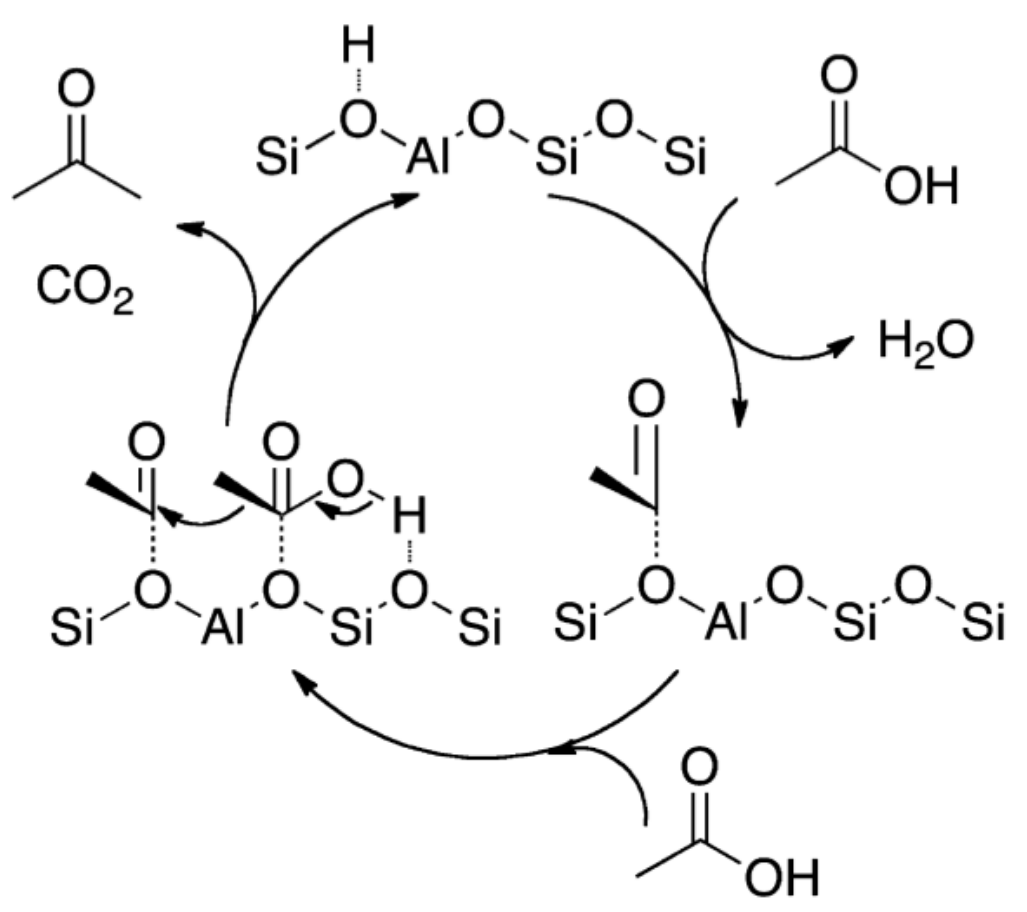


(a)
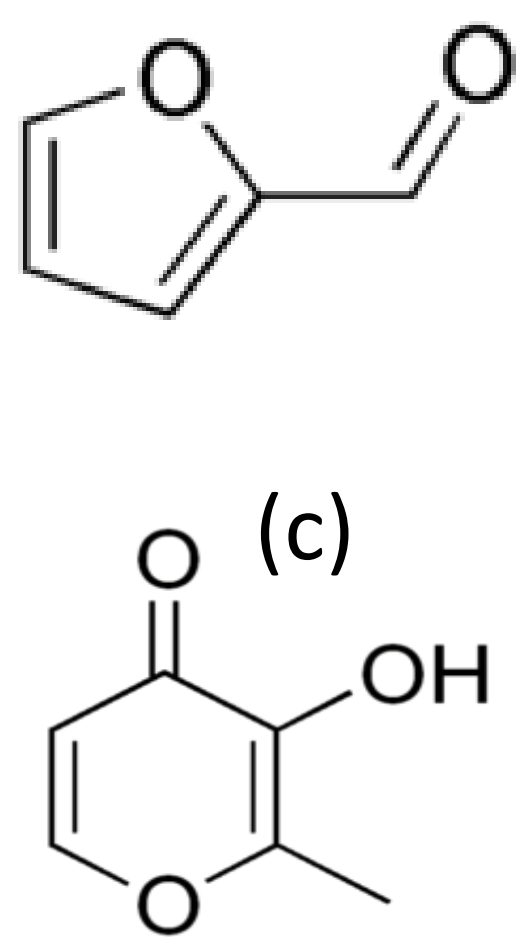

(e)

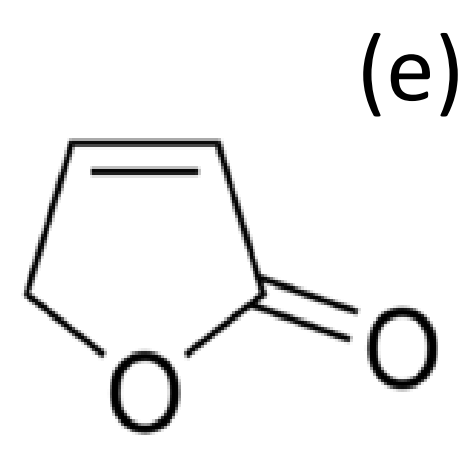

(b)

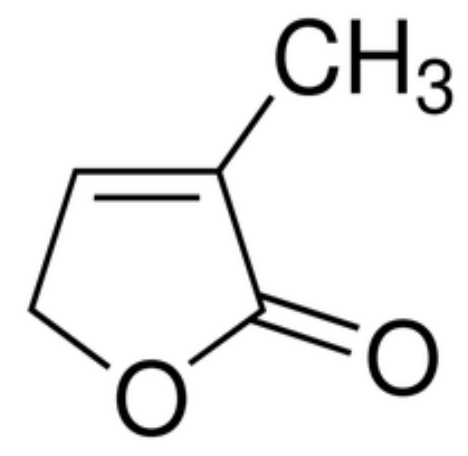

(d)

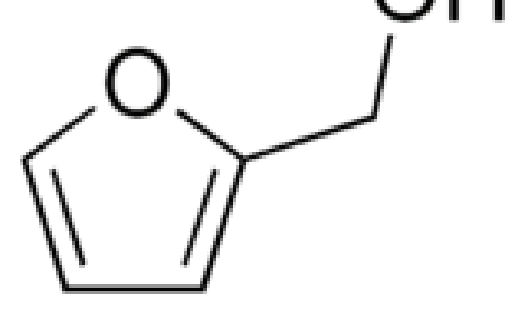

Figure 4. Typical unsaturated heterocyclic compounds found in pyrolysis oil. (a) Furfural; (b) 3methyl-2 furanone; (c) Maltol (or 3-Hydroxy-2-methyl-4H-pyran-4one); (d) 2-Furanmethanol (or Furfuryl alcohol); (e) 5H-furan-2one ; (f) 5-hydroxymethylfurfural (HMF).

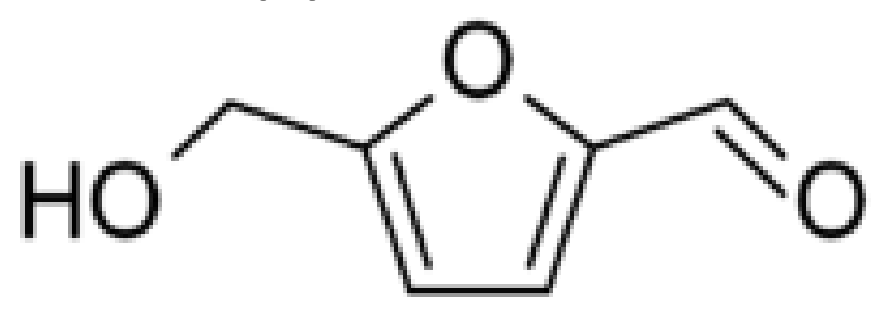




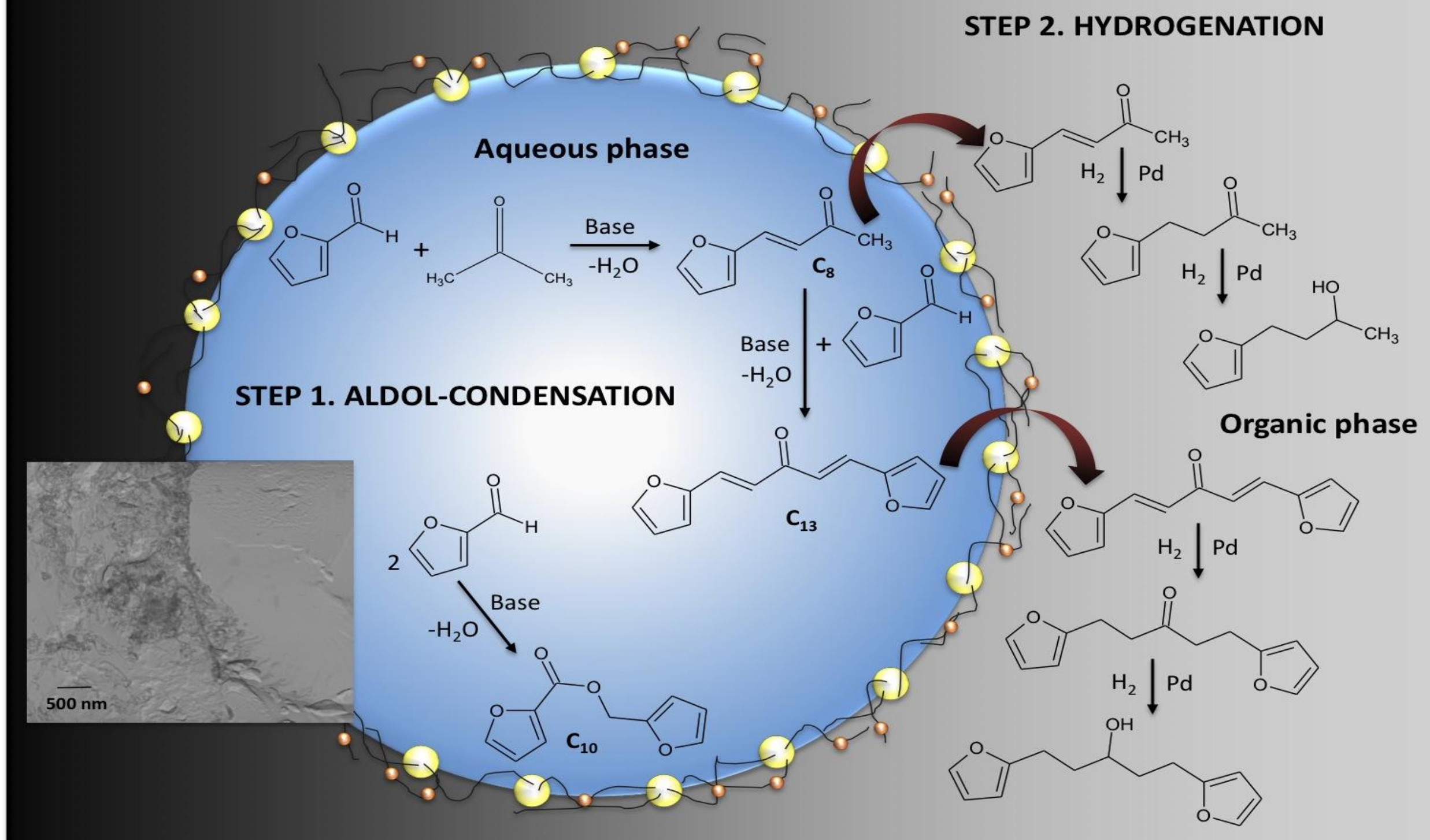

Figure 5. Schematic illustration of the aldol-condensation and hydrogenation reactions taking place at the water/oil interface in nanohybrid-stabilized emulsions [47]. 


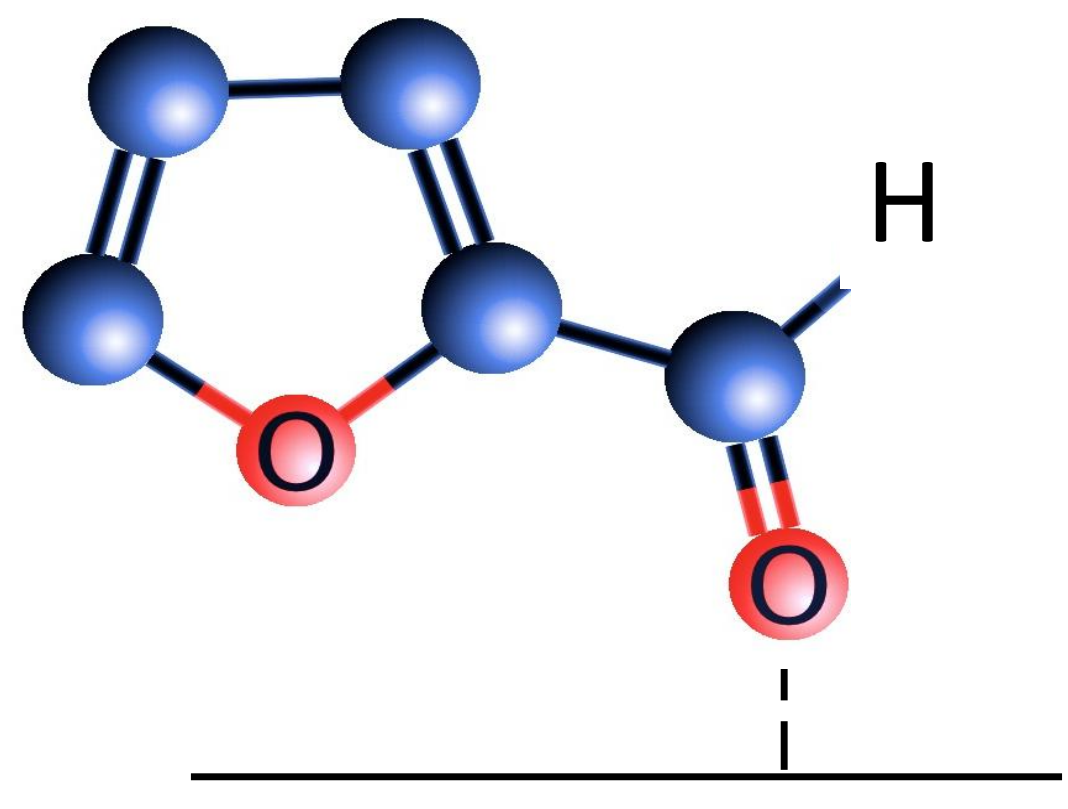

$\eta 1$-(O-aldehyde)

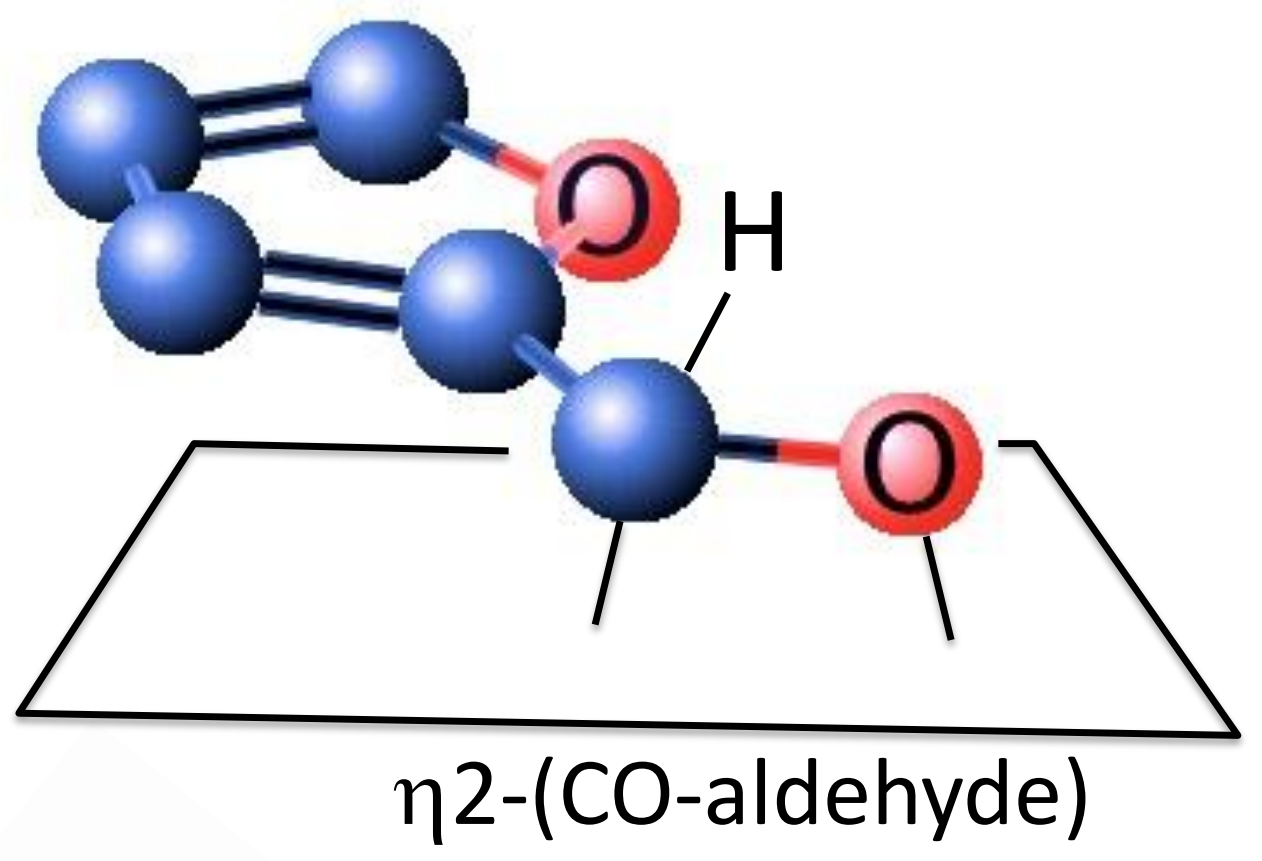

Figure 6. Different surface species for the adsorption of furfural on metals.

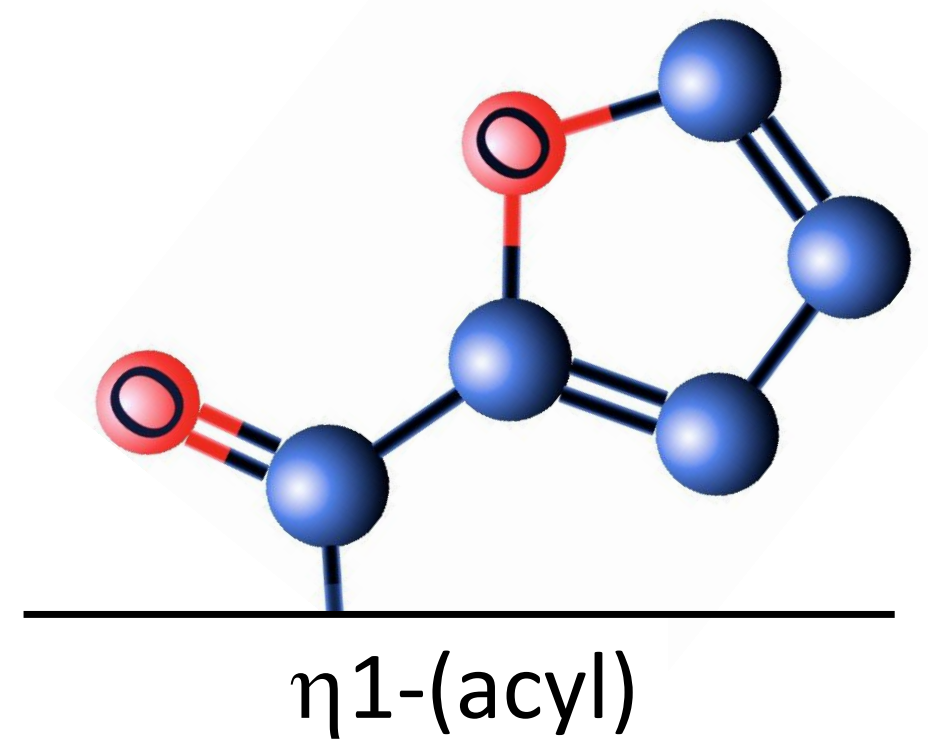




$$
E_{a d s}=16.4 \mathrm{~kJ} / \mathrm{mol}
$$

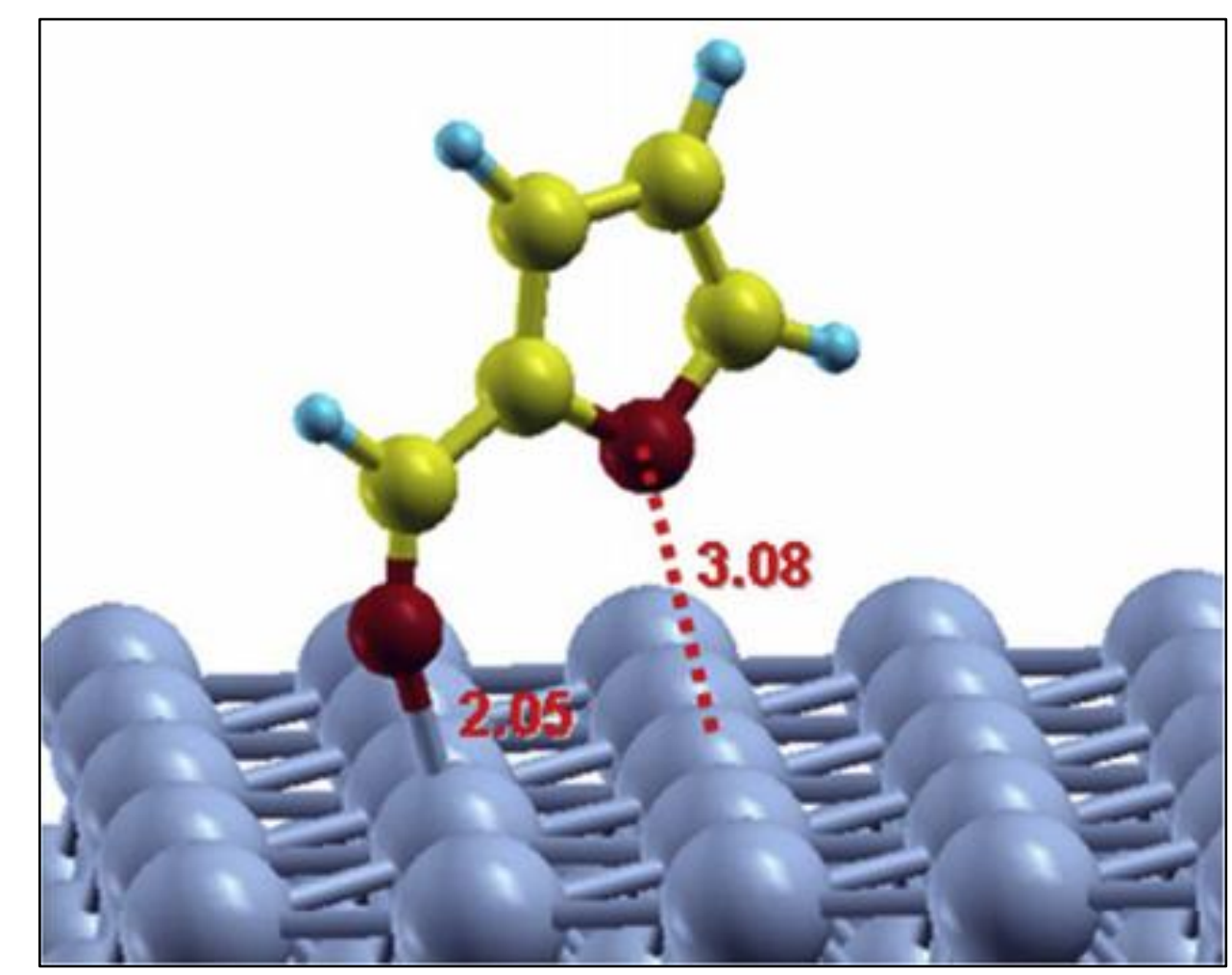

$\mathrm{Cu}(111)$
$E_{a d s}=55.4 \mathrm{~kJ} / \mathrm{mol}$

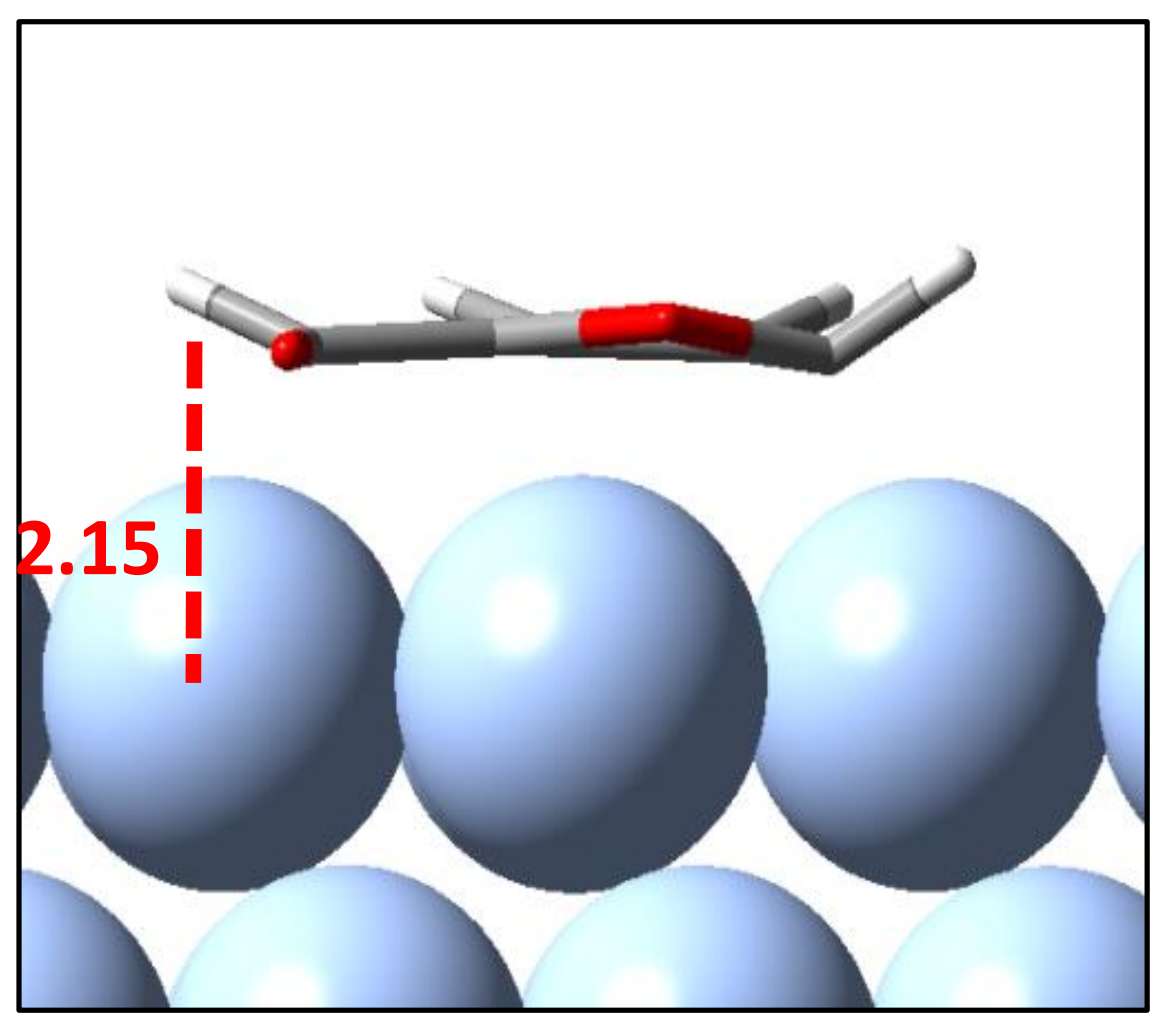

\section{$\operatorname{Pd}(111)$}

Figure 7. Preferred adsorption configurations of furfural on $\mathrm{Cu}(111)$, from ref. [62] and $\operatorname{Pd}(111)$ from ref. [71] 


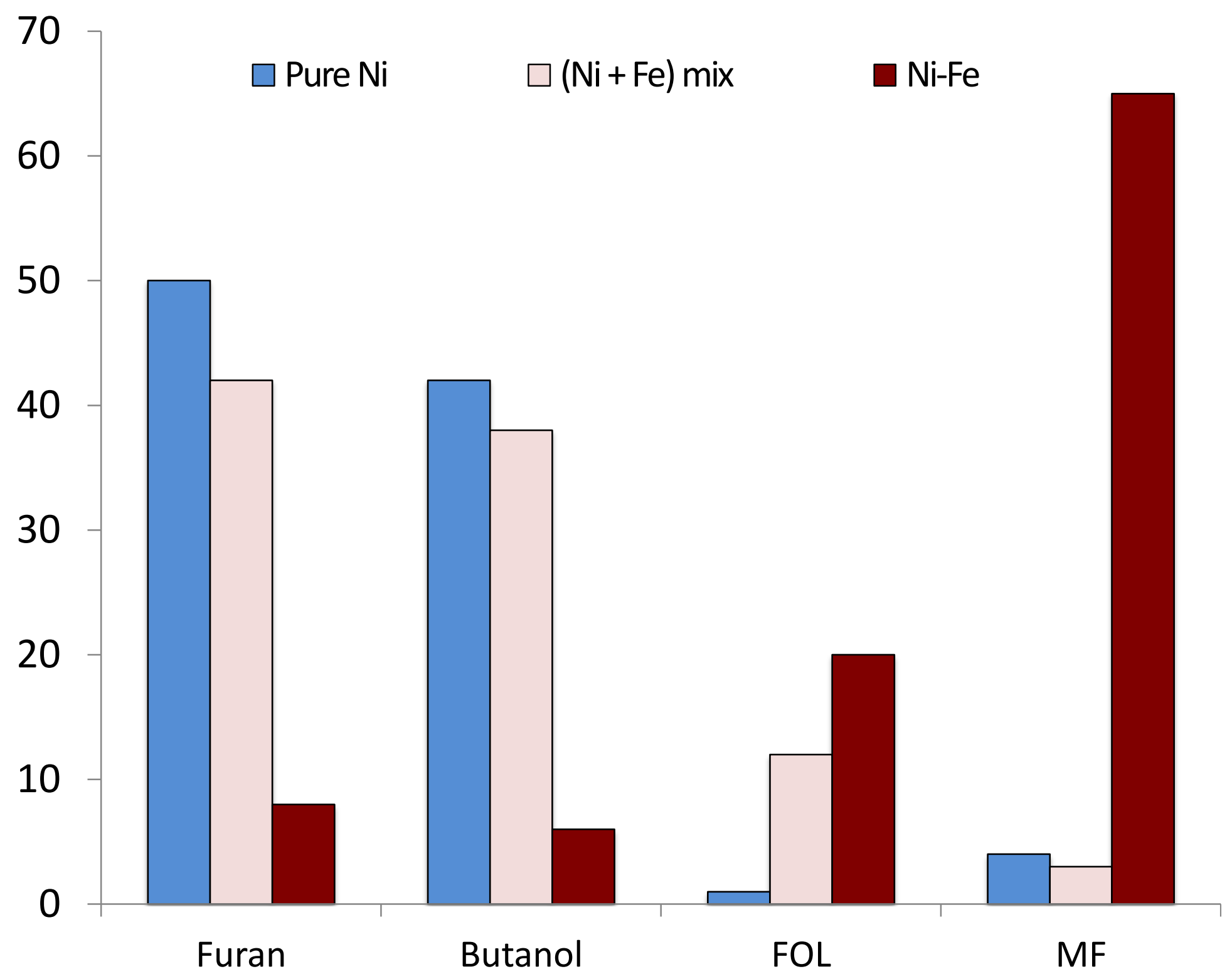

Figure 8. Product selectivity at the same overall conversion of furfural over different metal catalysts, from ref. [81]. 

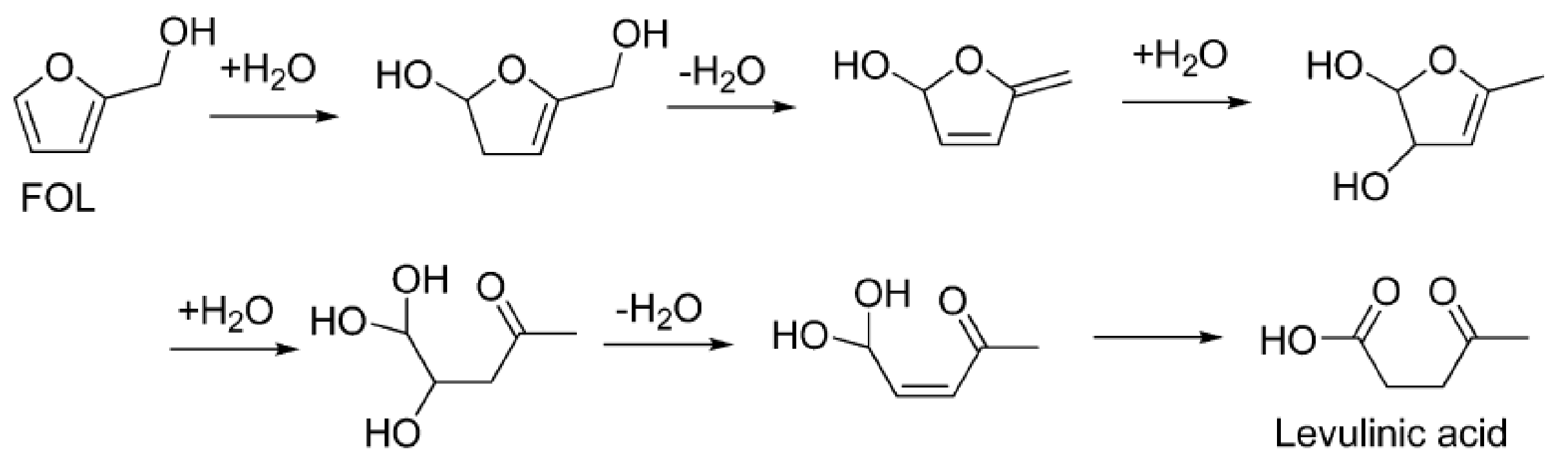

Figure 9. Proposed reaction pathway for the ring opening of furfuryl alcohol to levulinic acid involving a series of hydration and dehydration steps, from [54]. 


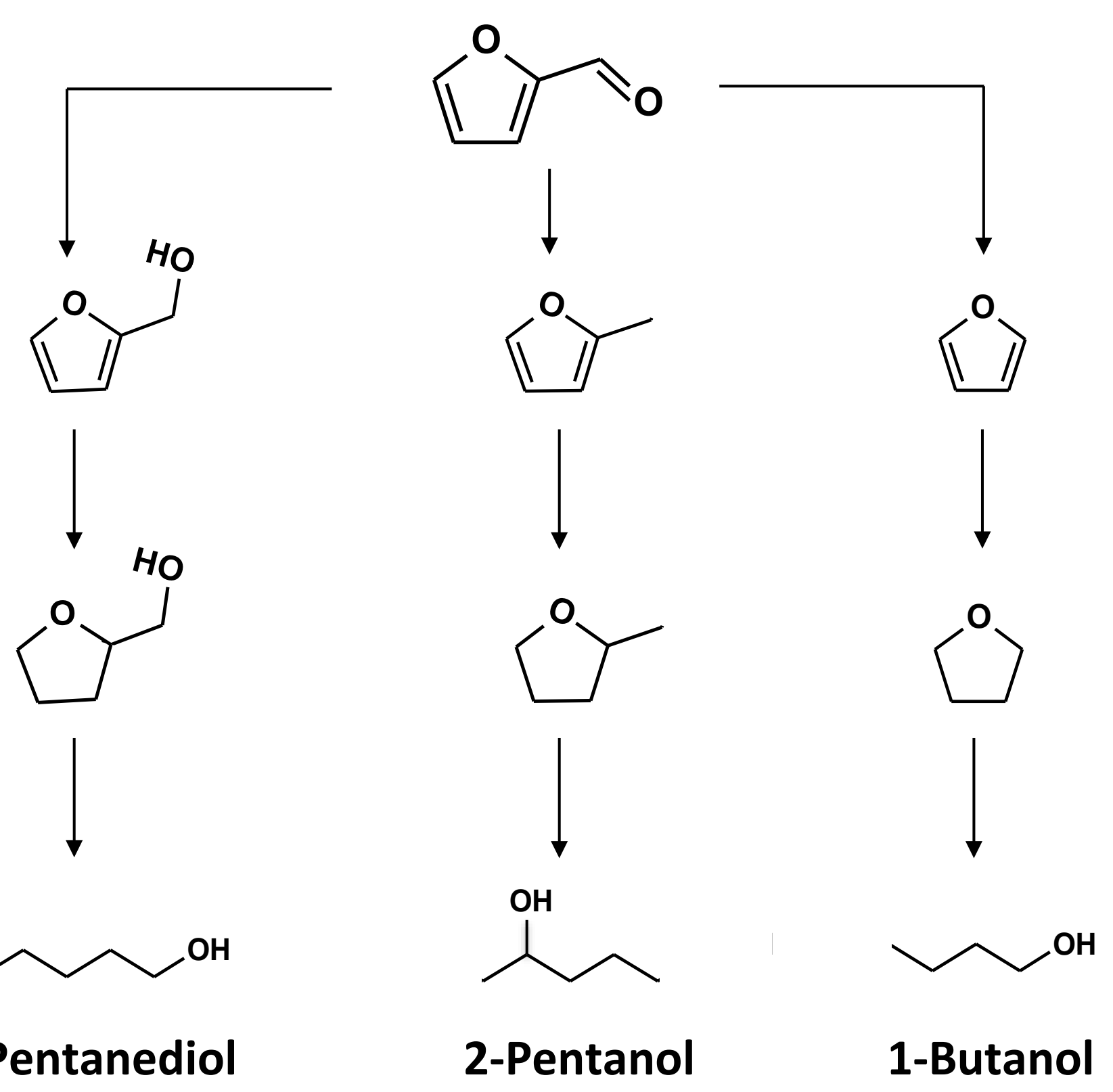

Figure 10. Ring opening of furfural after initial hydrogenation, hydrogenolysis, or decarbonylation reactions on metal catalysts. 
Figure 11. Possible reaction pathways occurring over supported Ru catalysts

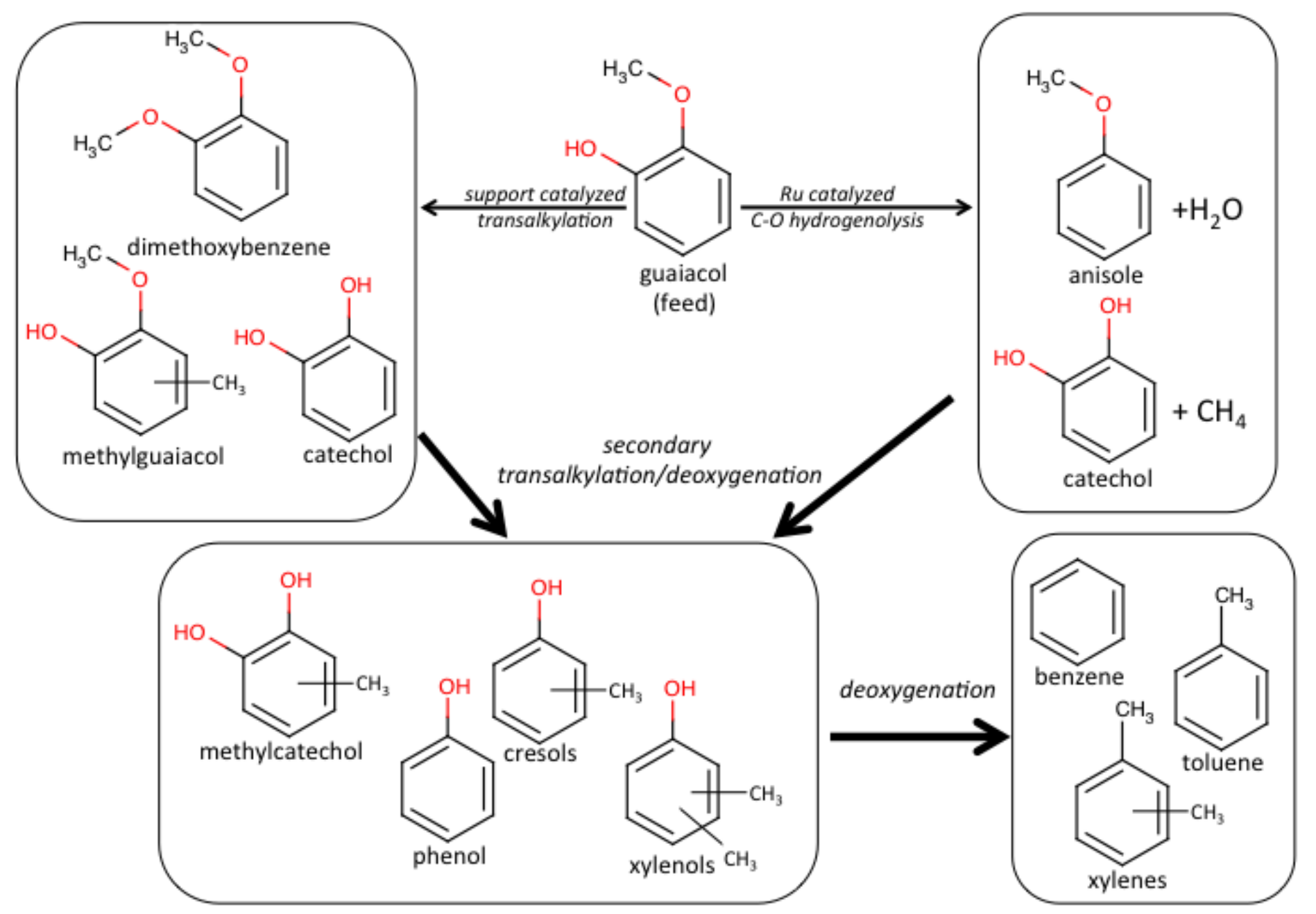


Figure 12. Proposed reaction pathways for the conversion of $m$-cresol over metals with varying oxophilicity and hydrogenation activities, in the absence of strong acid sites, from ref. [117].

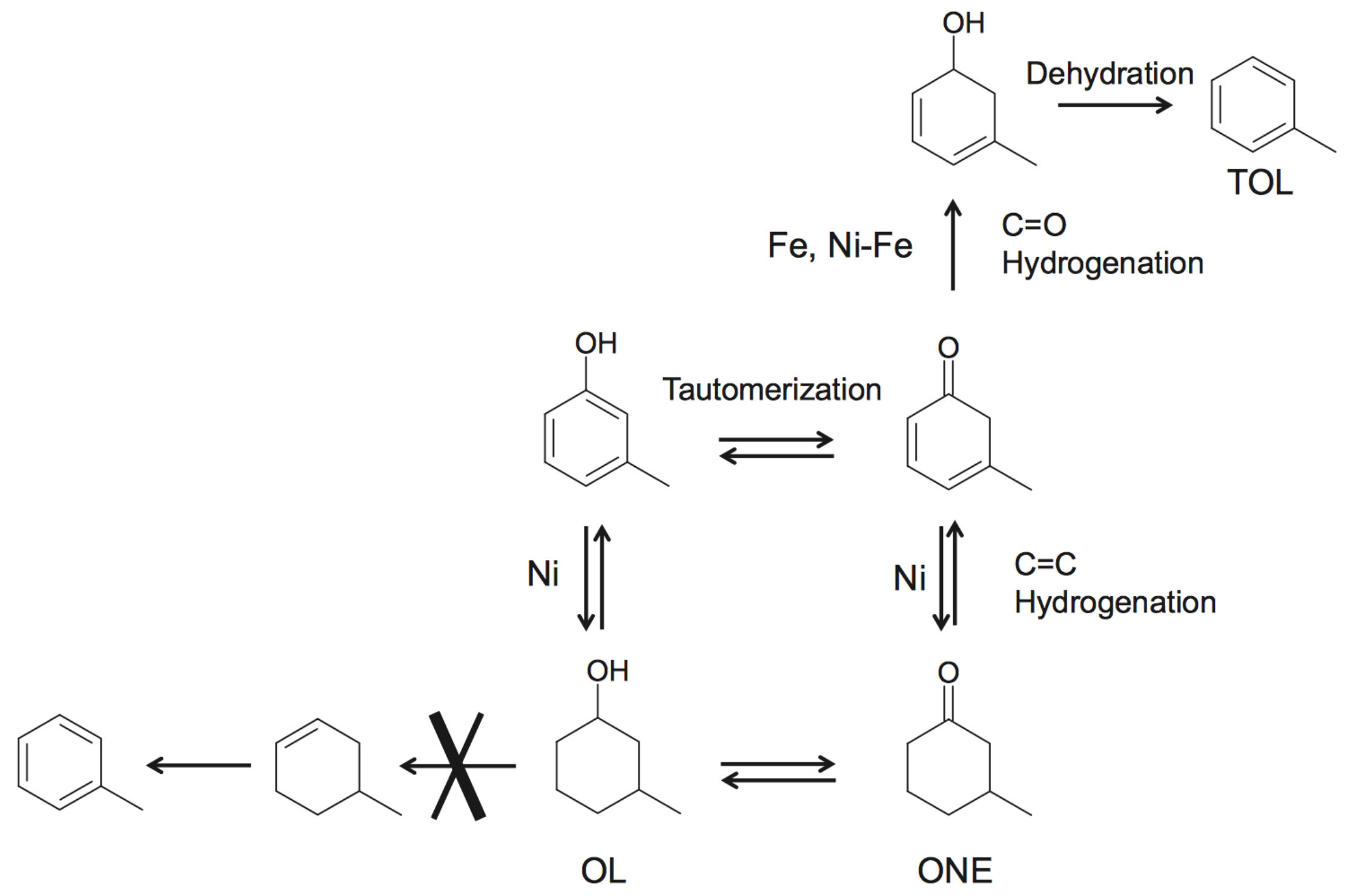


Table 2. Conversion of $\mathrm{m}$-cresol and di/monoalkylated products ratio from the alkylation reaction of $\mathrm{m}$-cresol and 2-propanol at $200^{\circ} \mathrm{C}$ and $700 \mathrm{psi}$ of He over untreated and functionalized HY zeolite (Si/Al molar ratio: 30). Feed: isopropanol/mcresol molar ratio: 3; total molar concentration: $2 \mathrm{M}$. From ref. [119]

\begin{tabular}{|c|c|c|c|c|}
\hline \multirow{2}{*}{ Zeolite } & \multicolumn{2}{|c|}{$\mathbf{3}$ h reaction } & \multicolumn{2}{c|}{$22 \mathrm{~h}$ reaction } \\
\cline { 2 - 5 } & $\begin{array}{c}\text { m-cresol } \\
\text { conversion }\end{array}$ & $\begin{array}{c}\text { di / mono- } \\
\text { alkylated ratio }\end{array}$ & $\begin{array}{c}\text { m-cresol } \\
\text { conversion }\end{array}$ & $\begin{array}{c}\text { di / mono- } \\
\text { alkylated } \\
\text { ratio }\end{array}$ \\
\hline Untreated & 10.0 & 0.38 & 11.8 & 0.52 \\
\hline $\begin{array}{c}\text { OTS- } \\
\text { functionalized }\end{array}$ & 20.0 & 0.57 & 97.0 & 1.47 \\
\hline
\end{tabular}


Figure 13: route of hydrolysis followed by partial oxidation for the production of gluconic acid from levoglucosan.
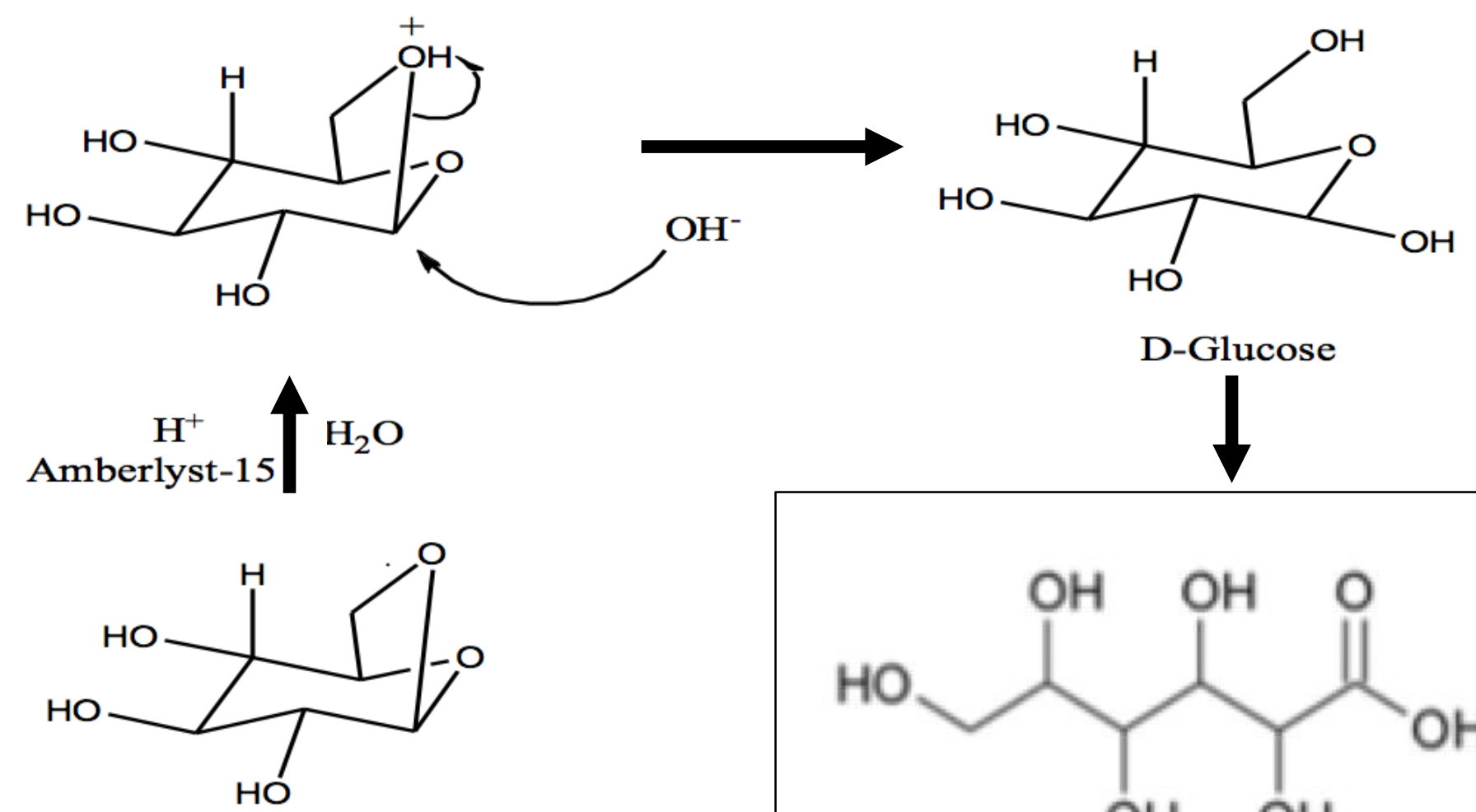

Levoglucosan

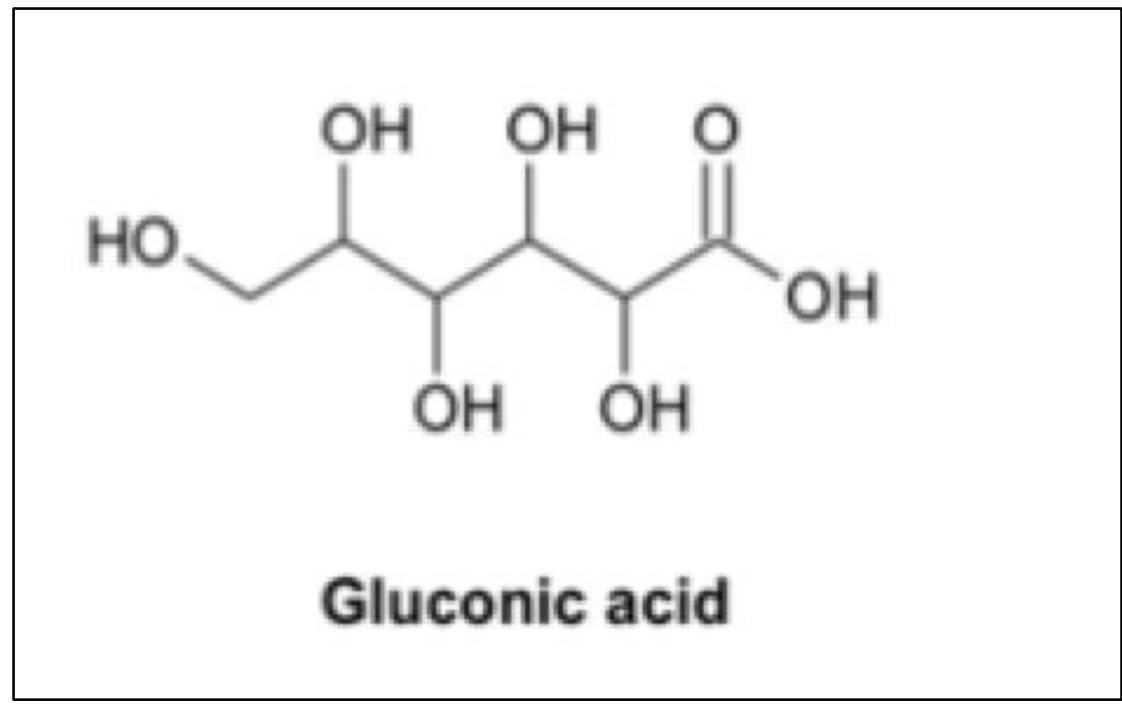




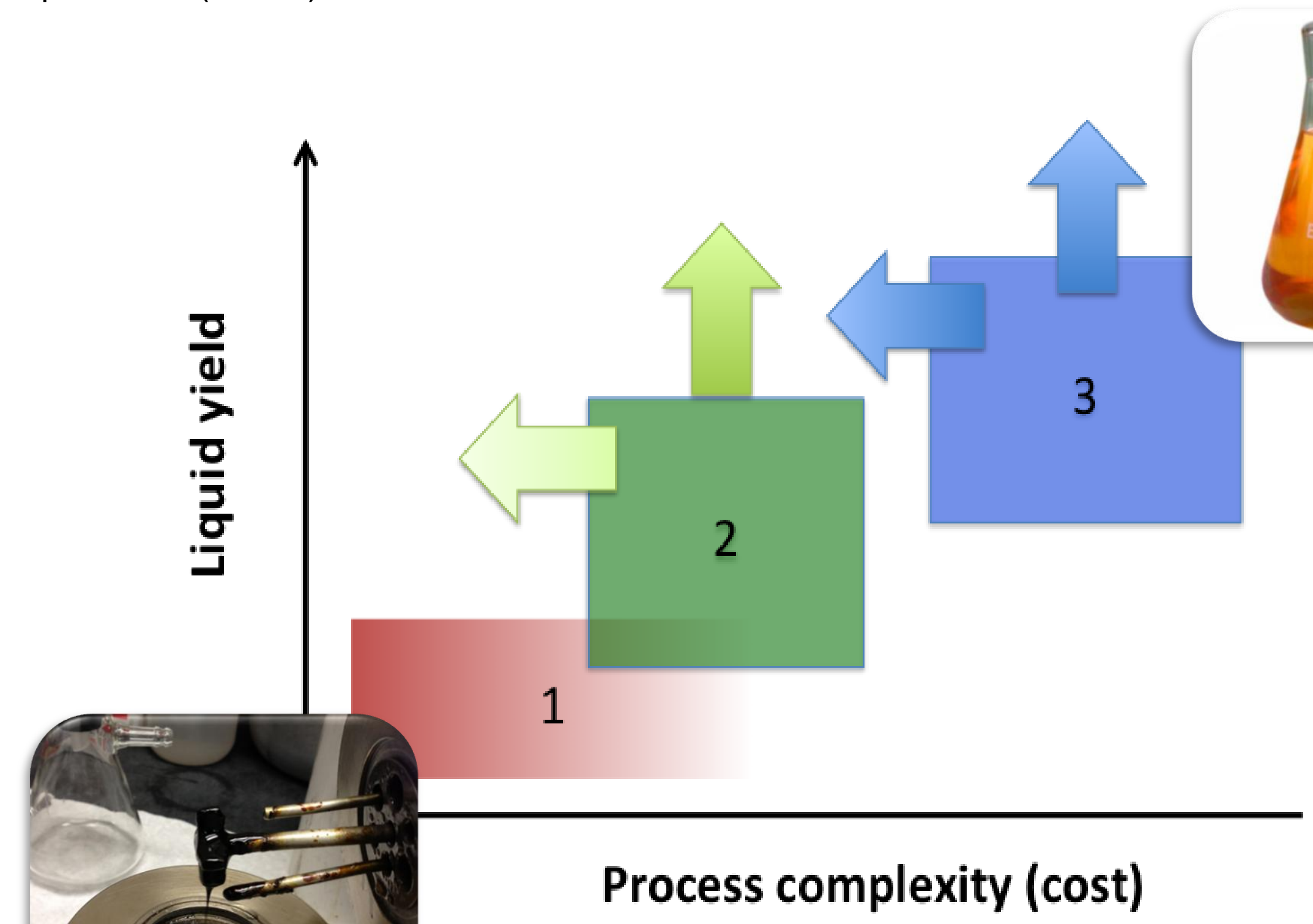

\section{Process complexity (cost)}

